\title{
DE LA ÉTICA CATÓLICA A LA ÉTICADE LA POBREZA: HACIA UNA TESIS SOBRE LAS IDEAS Y CREENCIAS RELIGIOSAS COMO FACTOR DE REZAGO SOCIOECONÓMICO EN LA POBLACIÓN MEXICANA DE LOS ESTADOS UNIDOS
}

\author{
Por \\ Rafael Arriaga Martínez*
}

\begin{abstract}
RESUMEN
En este artículo pretendemos fundamentar una tesis cuya proposición mayor postula la posibilidad de determinar la influencia de las ideas y creencias religiosas en la conducta económica de los mexicanos residentes en los Estados Unidos. Como concepto clave de la discusión, aquí la religión es definida de acuerdo con uno de los corolarios de la visión weberiana de la misma, a saber, como vehículo ético susceptible de frenar o estimular el ascenso social de los grupos sociales. Es pues, en torno a estos dos enunciados, que hemos concatenado la mayor parte de la base teórica, conceptual y metodológica desplegada en este trabajo.
\end{abstract}

\begin{abstract}
This article pretends to found a thesis which major preposition postulates the possibility to determine the influence in the ideas and religious beliefs in the economic behavior of Mexican residents in the United States. As a key concept in this discussion, in this case, religion is defined according to one of the corollaries of Max Weber's vision about religion: an ethic vehicle capable of stoping or stimulating the social ascent of social groups. Therefore, around this two statements we concatenated a wide part of theorical, conceptual and methodological basis of this work.
\end{abstract}

\footnotetext{
* Investigador del Instituto de Investigaciones Sociales de la Universidad Autónoma de Baja California.E-mail: rarriaga@faro.ens.uabc.mx

N. del E. Este artículo se acept6 en mayo de 1997 para ser publicado en Estudios Fronterizos.
} 


\section{INTRODUCCIÓN}

La notoriedad de los mexicanos en los Estados Unidos ${ }^{1}$ no sólo descansa en parámetros demográficos. Su presencia destaca también por sus altos índices de pobreza. Entre las respuestas que se han formulado en torno a este problema podriamos citar aquellos sistemas explicativos extraídos de teorías como la del colonialismo interno y del ejército industrial de reserva, teorías que, como se ha de saber, tienen sus fundamentos metodológicos en la lucha de clases. A partir de un breve examen de sus premisas señalamos las insuficiencias que desde nuestro punto de vista conlleva un análisis supeditado a la pura estructura de producción y las relaciones sociales de producción.

Analizamos también los postulados o supuestos fundamentales sobre los que se organiza la tesis de la discriminación racial. Si bien es cierto que los prejuicios raciales y las prácticas discriminatorias constituyen fuerzas que limitan las posibilidades de las mînorías no sólo de ascenso social sino de verdadera integración económica, también es cierto que ésta pierde peso desde que se intenta correlacionar el grado de discriminación histórica con los resultados obtenidos por las mismas. En todo caso esta es la conclusión a la que nos ha llevado un breve análisis sociocomparativo en el que, por una parte, se resume la experiencia histórica de algunos grupos étnicos en materia de discriminación racial y por la otra se destaca el logro socioeconómico realizado por los mismos.

Una vez evacuados del analisis ambos enfoques, pasamos a fundamentar una tesis conforme a las categorias de la teoria weberiana del conocimiento. Se trata de un mecanismo teórico-metodológico que nos permite,

1 Cabe advertir que este estudio contempla la situación de los mexicanos desde una perspectiva de totalidad. De manera que por población de origen mexicano o por mexicanos de los Estados Unidos, hemos de referimos al mismo cuerpo demográfico que figura de una manera monolítica en los censos de población divulgados por el U.S. Bureau of the Census. De la misma manera, las operaciones que en lo fundamental tengan como objeto medir contrastes socioeconómicos entre los diferentes grupos estarán igualmente contempladas desde una perspectiva que hace abstracción de la variable generacional. Bien que los datos censales ignoran la calidad migratoria de la población mexicana u otra "nacida en el extranjero" (Foreign bom), estos datos no incluyen, por lo menos en gran medida, a las personas en situación migratoria irregular. En todo caso esto es to que presupone las deformaciones estructurales demográficas que provocan la presencia de los ilegales no recensados, como por ejemplo sobre la tasa de mortalidad, la cual aparece desproporcionada en relación al número de personas recensadas (Robinson en Boutang, Garson, Silberman, 1986:45-47). La clandestinidad y su cortejo de consecuencias sociales hace de los indocurnentados un grupo (sui-generis), verdaderamente aparte. En 1980, según el Servicio de Inmigración y Naturalización (SLN), había en los Estados Unidos alrededor de 2000000 de indocumentados, de los cuales 900000 eran originarios de México. (Bureau of the Census U.S.,1983:9). 
al estudiar un fenómeno, determinar la importancia de $\mathrm{x}$ punto de vista entre $\mathrm{n}$ puntos de vista.

Es pues desde esta perspectiva y a partir de esta concepción particular de la realidad social que postulamos la posibilidad de conceptualizar las ideas y las creencias religiosas como factor específico de rezago socioeconómico. Esto es en lo que respecta al caso de los mexicanos de los Estados Unidos. Como concepto clave de la discusión, aquí la religión será definida de acuerdo con uno de los corolarios de la visión weberiana de la misma, a saber, como vehículo ético susceptible de frenar o estimular el ascenso social de los grupos sociales. Nos encontramos, pues, frente a un enunciado al cual hemos concatenado parte de la base térica, conceptual y metodológica desplegada en este trabajo.

En lo que respecta a la base teórica referida, ésta nos ofrece una discusión la cual se organiza, esencialmente, en torno a dos enfoques cuyas escuelas encabezadas por Marx y Weber destacan por sus posiciones antitéticas.

En lo que respecta a la base conceptual, ésta se resume a un cúmulo de elementos que nos indican:

1) Divergencia en cuanto a desarrollo económico entre las naciones de cultura protestante y las de cultura católica.

2) Desigualdades sociales entre los diferentes grupos confesionales de los Estados Unidos.

3) La importancia de la variable confesional como factor generador de tales desigualdades.

El problema específico de la aplicación del método comprensivo al objeto de estudio citado es abordado en la última parte de este trabajo. Se trata de un andamiaje técnico-metodológico diseñado con el propósito de llevar al campo la observación de las premisas en las que se sustenta nuestra hipotesis de trabajo. En esta parte del artículo definimos los espacios de observación, el universo social, las técnicas de observación, los instrumentos de recolección de la información, así como el número de personas encuestadas.

\section{DATOS PRELIMINARES}

De acuerdo con los censos de población de los Estados Unidos para 1990, casi 13500000 de personas declararon ser de ascendencia mexicana, y de éstos, casi 4500000 afirmaron haber nacido en México (Bureau of the Census U.S., 1992:17,42). En otros términos, el 33.3\% de este grupo nacional ha llegado a Estados Unidos en calidad de inmigrante, de manera legal e ilegal. La inmigración, como una constante importante observada 
desde $1909,{ }^{2}$ sumada a la alta fecundidad de las mujeres mexicanas, han hecho de esta minoría, después de los negros, la segunda más importante de Estados Unidos. En los últimos veinte años su tasa de crecimiento demográfico ha alcanzado un $159.5 \%^{3}$ y si esta tendencia persiste, es seguro que los mexicanos, junto con otros grupos hispanos no tardarán más de un lustro para figurar dentro del paisaje étnico-racial como la primera minoria a nivel nacional. ${ }^{4}$ Aun cuando dichas tendencias se pudieran revertir, incluso de una manera drástica (restricción migratoria, deportación masiva, etcétera), la importancia de esta minoría es en la actualidad de primer orden en el sudoeste de los Estados Unidos, pues es ahí en donde se concentra el $83.8 \%$ de toda la poblacion de ascendencia mexicana. Asf pues, en los estados de California, Arizona, Nuevo México, Texas, Nevada y Colorado dos de cada $\mathbf{1 0}$ habitantes son de ascendencia mexicana (Bureau of the Census U.S., 1992).

Por otra parte, es preciso agregar que la notoriedad de los mexicanos en los Estados Unidos no sólo descansa en parámetros demográficos. Su presencia destaca, antes que todo, por sus altos índices de pobreza. En efecto, a nivel nacional, casi una tercera parte de la población de ascendencia mexicana vive por debajo de los límites que definen la pobreza.

De manera general, se dice que la pobreza en Estados Unidos es, desde el punto de vista étnico, de "mediana y alta visibilidad", pues ésta afecta al $28.1 \%$ de los mexicanos; $31.9 \%$ de los afroamericanos y casi uno de dos puertorriqueños radicados en Estados Unidos (40.6\%) perciben un salario que los coloca dentro de esta definicion social (Bureau of the Census U.S., $1992: 456 ; 1994: 49)$. La magnitud de la pobreza entre estos grupos étnicos es tal que representa uno de los aspectos de la realidad social de los Estados Unidos más impactantes. Este hecho social es más obvio si se considera que la pobreza entre los blancos $(10.7 \%)^{6}$ es casi tres veces menor que la de aquéllos (figura 1). Es pues de este hecho social que se desprende la interrogante mayor de nuestro trabajo.

2 Sólo la crisis de los años treinta y la lenta recuperación económica de los años cuarenta, frenan el número creciente de inmigrantes mexicanos (Cf. Bureau of the CensusU.S., 1978:107; 1992:11).

3 En 1970, la población de ascendencia mexicana apenas sobrepasaba los 4500000 .

4 Para el af́o 2050 la proporción de la comunidad hispana (21\%) habrá de superar a la de 1a comunidad afroestadounidense $(16 \%)$ en 5 puntos porcentuales. $\mathrm{Cf}$. proyecciones realizadas por los censos de población (Bureau of the Census U.S., 1993:7).

5 De acuerdo con una definición del departamento de los censos de los Estados Unidos una persona se considera pobre cuando ésta percibe anualmente 6800 dólares o menos. (U.S Bureau of the Census U.S., 1992:427).

6 De una manera general los censos se refieren a las personas caucáseas de ascendencia europea. 


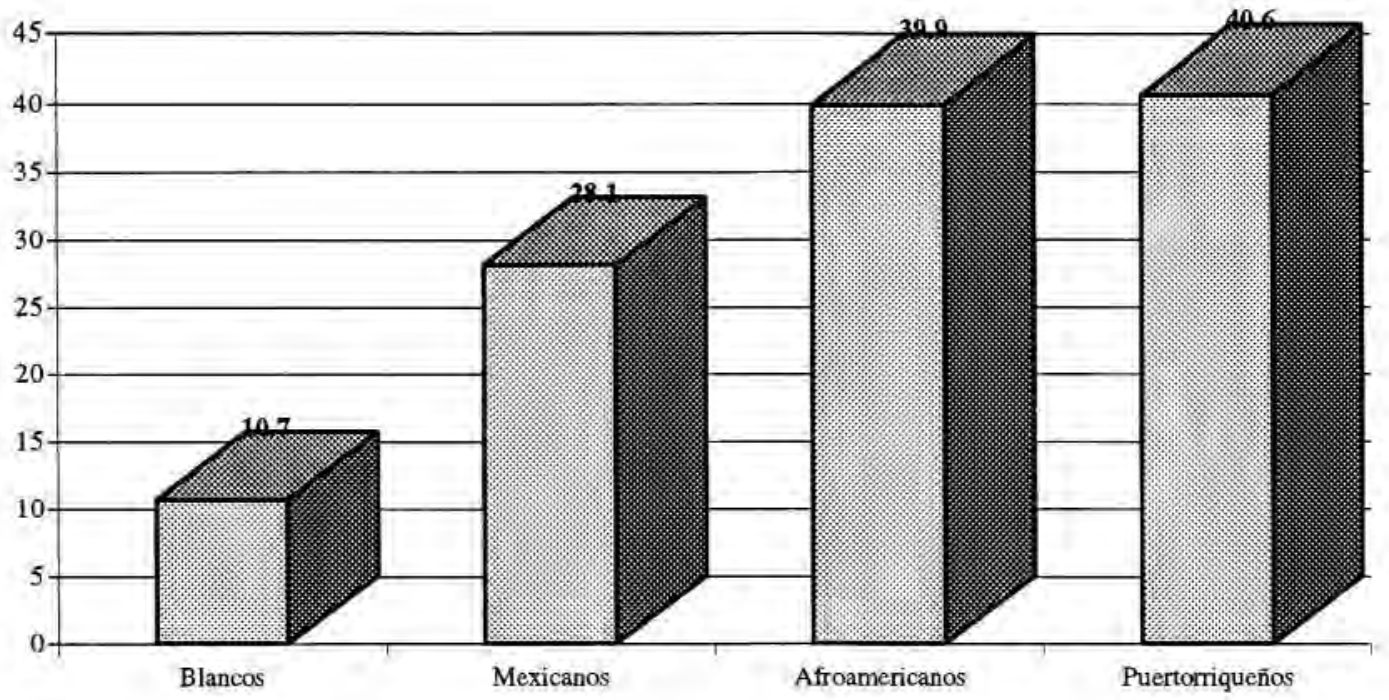

Figura 1. Proporción de personas bajo el umbral de la pobreza.

Fuente: Bureau of the Census U.S., 1992:456; 1994:49. 


\section{LA CONDICIÓN SOCIAL DE LA POBLACIÓN DE ASCENDEN- CIA MEXICANA DESDE LA PERPECTIVA DEL MÉTODO DE ANÁLISIS MARXISTA}

Es menester recordar que un buen número de sociólogos, antropólogos e historiadores, especializados en el tema de la etnicidad, han pretendido darle una respuesta al fenómeno de la pobreza entre estas etnias ${ }^{7}$. Algunas de estas respuestas, particularmente las que se formularon durante los años sesenta y setenta al calor de los incendios de Watts, el movimiento chicano y otros conflictos raciales, han encontrado sustento en sistemas explicativos extraídos de teorías como la del "colonialismo intemo" y la del "ejército industrial de reserva", teorías que, como se sabe tienen sus fundamentos metodológicos en la lucha de clases.

En ambos casos se considera la situación actual de los mexicanos en Estados Unidos como el resultado de un largo proceso de opresión política y explotación económica que tiene como punto de partida histórica la conquista de lo que hoy es el suroeste de los Estados Unidos o lo que fue hasta 1848 el norte de México. Desde esta última perspectiva, la historia de los mexicanos es planteada en términos de explotación sustentada sobre la base de las diferencias de clase y raza. Desde el punto de vista racial, el racismo como ideología es la base sobre la cual se ha podido perpetuar la estructura colonial del suroeste, diría en un momento dado Rodolfo Acuña (1976:10). De la misma manera, para Almaguer el racismo no es sólo una cuestion de dominación ideológica, sino que basada en la discriminación racial y cultural se ha formado una reserva de mano barata y de plusvalía (1975:10). Algunos otros autores sostienen que, como ejército industrial de reserva, "la mano de obra mexicana ha contribuido de manera importante a la expansión industrial y a la prosperidad de los Estados Unidos" (Arrollo Cisneros, Gómez-Quiñones, 1978:10).

Como se podrá observar, en las páginas siguientes nos propondremos señalar las insuficiencias que desde nuestro punto de vista comporta dicho enfoque.

\section{ETNIA DISCRIMINACIÓN Y POBREZA}

Desde el punto de vista histórico, la correlación entre etnia y marginación económica no es un fenómeno nuevo ni exclusivo al caso de los mexicanos.

7 "Whats has happened to Blacks, Hispanics, American Indians, and other minorités in the $80, s^{\prime \prime}$, es el título de un estudio que muestra en toda su elocuencia la realidad social de estos grupos en los Estados Unidos. 
Alemanes, irlandeses, eslavos, italianos, judíos de los países del este de Europa, en fin, todos los grupos étnicos o nacionales que llegaron en olas sucesivas a los Estados Unidos desde esta parte del hemisferio, no solamente vivieron en el último peldaño de la escala social durante por lo menos una larga generación, sino que además fueron objeto de violencia y de prácticas discriminatorias sistematizadas (Cf. Morison, Commager, 1951; Ertel, Fabre, Marienstras, 1979).

La intolerancia racial es un hecho que se observa a lo largo de toda la historia de los Estados Unidos, es una práctica social a la cual, incluso científicos e intelectuales le han llegado a dar cuerpo a través de teorías e ideologías, ${ }^{8}$

Se dice que casi todos estos grupos se han fundido al paso de las generaciones dentro de un paisaje racial inminentemente blanco, en el que sólo las divisiones de orden confesional han podido persistir; que de su origen nacional no les ha quedado más que la consonancia de sus apellidos, el gusto pronunciado por los platillos de sus antepasados, la afiliacion religiosa a su iglesia, y la noción de una identidad remota, esporádicamente reivindicada pero sólo para honrar a sus genealogías (Cf. Alba, 1990).

Si bien el "melting pot" ha sido un éxito relativo para estos grupos de "cultura blanca", para los negros, mexicanos y otros grupos, la ideología de la mezcla de razas ha sido un fracaso resonante. La pobreza endémica y los bajos índices de exogamia de los afroamericanos y mexicanos podría ser una prueba palpable de ello.'

De manera general, Sowell (1986:203) observa los fenómenos de la desagregación residencial y la exogamia en algunos grupos étnicos y señala que éstos se dan con mayor frecuencia entre los miembros de los estratos más elevados. Aquí la noción del éxito económico aparece como la condición sine qu non para que los grupos culturalmente distintos puedan ser aceptados por la sociedad. En otras palabras, sólo el ascenso social de los grupos étnicos los podría ayudar a superar la barrera racial y

8 Los esfuerzos de intelectuales como Gobineau, Chamberlain y Galton por acreditar la tesis de la superioridad biológica de la raza blanca son ampliamente difundidos por el "movimiento nativista" a lo largo del siglo XDX, quien preocupado por preservar el fondo cultural WASP -white anglo-saxon and protestant- que hasta entonces había dominado y definido el carácter nacional, lanza una cruzada etnológica en contra de los inmigrantes originarios de Europa del sur y del este, calificados como "miembros vencidos de las razas vencidas". La obra del conde de Gobineau "Sur l'inégalite des races humaines" (sobre la desigualdad de las razas humanas) es un testimonio de tales esfuerzos (1854).

9 El índice de exogamia entre los cónyuges mexicanos es del $13.2 \%$ para los hombres y $14.2 \%$ para las mujeres. Los datos al respecto no especifican la proporción de parejas formadas entre mexicanos y blancos ( Bureau of the Census U.S., 1992:45). 
cultural que los separa de la integración, tal y como en el pasado los europeos tuvieron que superar las de orden nacional y cultural, dejando pendiente la de orden confesional.

En el caso particular de los mexicanos, Grebler y Moore anotan de acuerdo con estudios respectivos, que el $50 \%$ de los mexicanos con mayores ingresos de Los Ángeles viven en áreas residenciales dominadas por blancos y que en la misma proporción jóvenes mexicanos de estas mismas áreas residenciales se casan fuera de su grupo (en Sowell, 1986:244).

Dada la ínfima proporción de familias mexicanas concentradas en la punta de la pirámide social, estos mismos datos nos pudieran revelar más un fenómeno de segregación residencial que un proceso de integración. Si por familias con mayores ingresos entendiéramos aquellas cuyos ingresos rebasan los 50,000 dólares por año, cabria apuntar que a nivel nacional solo un 17\% de las familias hispanas alcanzan este nivel, (Bureau of the Census U.S., 1991:460), proporción realmente insignificante sobre todo si se le compara con el logro que han alcanzado algunos grupos étnicos de "formación" reciente, que han destacado por su rápido ascenso social. Como enseguida lo podremos ver, este es el caso de los japoneses, chinos, coreanos, filipinos e incluso vietnamitas.

\section{LOS ASIÁTICOS Y LOS HISPANOS VISTOS DESDE UNA PERSPECTIVA COMPARATIVA}

En 1989 el ingreso promedio familiar por año de cada uno de estos grupos étnicos se situó entre $\$ 29,772$ y $\$ 43,780$ dolares, siendo el de los vietnamitas el más bajo y el de los japoneses el más elevado. En el caso de los vietnamitas, sus ingresos por una parte casi alcanzan la media nacional -\$30,468-y por la otra rebasan con un amplio margen el ingreso promedio familiar de los mexicanos $-\$ 23,694$ un grupo étnico con características socioeconómicas de rango medio dentro de la serie de minorias hispanas (Cf. The Asian-American Encyclopedia, 1995; The Latino Encyclopedia, 1996:833; Bureau of the Census U.S., 1992:445). (Ver figura 2).

Lo mismo se podría decir respecto a los niveles de ingreso percápita, desempleo, posición dentro de la estructura del empleo y otros parámetros. En el caso del grupo más desfavorecido dentro de la serie de grupos asiáticos, esto es, el de los vietnamitas, su ingreso promedio familiar $-\$ 29,772$ - es significativamente superior no sólo al de los mexicanos sino también al de los cubanos — $\$ 27,294$, es decir, el grupo que más 
destaca dentro de la serie de grupos hispanos, ${ }^{10} \mathrm{y}$ al de los mexicanos (cf. supra), Respecto a este último grupo, los vietnamitas registran mejores niveles en casi todos los parámetros: ingreso percápita $(\$ 9,033.00$ contra $\$ 7,447)$ desempleo $(5.4 \%$ contra $8.2 \%$ ) y status laboral: el $47.1 \%$ de la mano de obra vietnamita es de oficina - actividades ligadas a la gestión de empresas, profesiones especializadas, ventas y apoyos técnicos y administrativos-contra solo un $32 \%$ en el caso de los mexicanos (The Asian-American Encyclopedia, 1995:1627; The Latino Encyclopedia, 1996:799; Bureau of the Census U.S., 1992:382, 383).

En el otro extremo de la escala, el liderazgo de los japonenes en casi todos los parámetros rebasa el marco de los grupos étnicos de ascendencia asiática. Con una tasa del $2 \%$ de desempleo, un ingreso percápita anual de $\$ 19,373$ y un 3\% de familias pobres, los japoneses han demostrado mayor dinamismo que la población blanca cuyos índices de pobreza familiar $(7.8 \%)$, desempleo $(4.7 \%)$ y niveles de ingresos por persona $(15,701.00)$ nos muestran la medida del progreso de los primeros y del rezago de los segundos. (The Asian-American Encyclopedia, 1995:737; Bureau of the Census U.S., 1992:383,454,459). (Ver figuras 3, 4 y 5).

De una manera general, los hispanos son tres veces más numerosos que los asiáticos ( $9 \%$ contra 2.9\%), y sin embargo ambos ocupan exactamente el mismo número de lugares en los colegios y universidades estadounidenses (4.7\%). (Bureau of the Census U.S., 1992:17; National Center for education Statistics, cit. en Morganthau, 1995). En este sentido las estadísticas no pueden ser más formales: en 1990, el $40 \%$ de los asiáticos de 25 años en adelante habían hecho 4 años y más de preparatoria contra el $10 \%$ en los hispanos y un poco más de $20 \%$ para los estadounidenses de ascendencia europea (The Asian-American Encyclopedia, 1995). Aún más, en el mundo de los negocios los asiáticosestadounidenses manejan mayores volúmenes de capital que los hispanos (Bureau of the Census U.S., 1992:528-529). De esta manera, la rentabilidad de los capitales sumada a los salarios explican la fuerte proporcion de familias asiáticas (41\%) con un ingreso medio igual o superior a los 50,000 dólares por año. Aquí, de nuevo los asiáticos superan a los blancos de ascendencia europea (33\%), y por supuesto a los mexicanos (17\%) (The Asian-American Encyclopedia, 1995; The Latino Encyclopedia, 1996:798).

${ }^{10}$ De acuerdo con la clasificación étnica manejada por los censos estadounidenses, la población de origen hispano -22 354000 personas - está conformada por cuatro grupos nacionales, de los cuales los mexicanos representan el $60.3 \%$, los puertorriquetios el $12.3 \%$, los cubanos el $4.6 \%$ y los originarios de otros puntos de América de habla hispana el $22.7 \%$. (Cf. U.S. Bureau of the Census, 1992:17). 


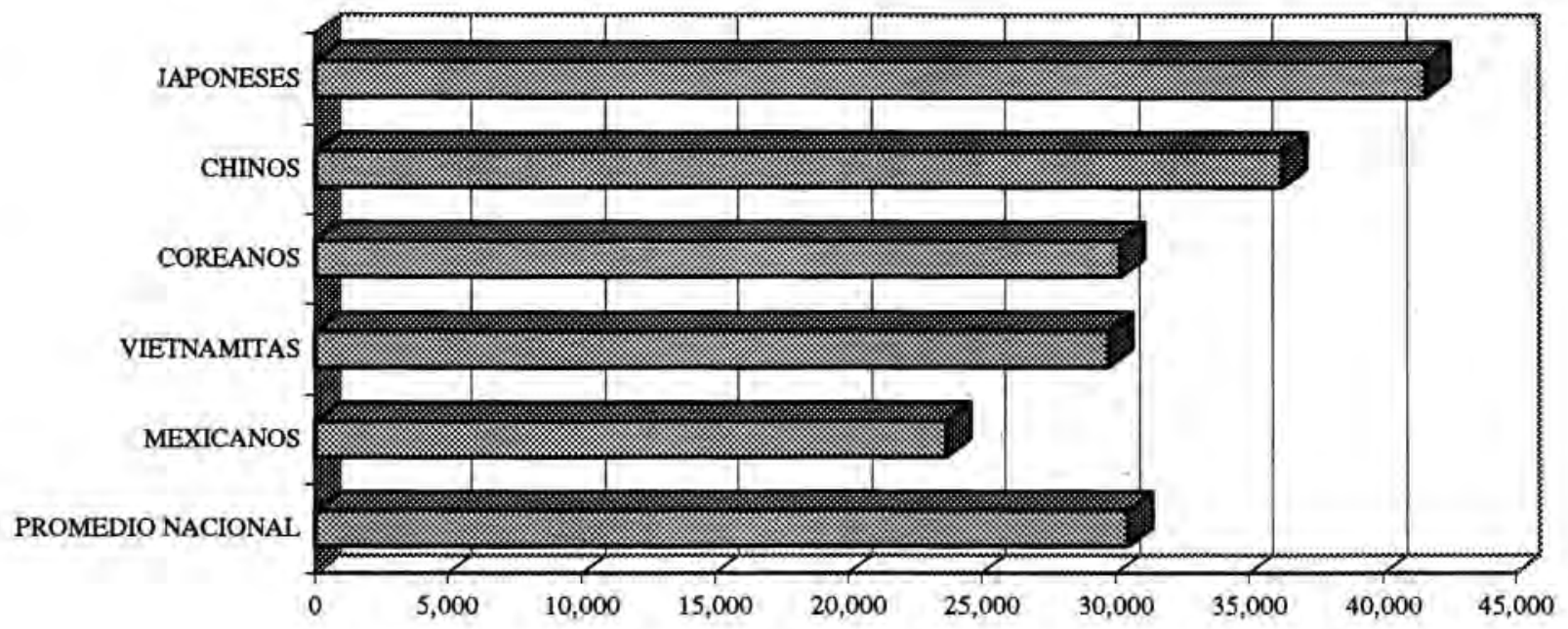

Figura 2. Ingreso promedio familiar, 1989 (en dólares constantes).

Fuente:Bureau of the Census U.S., 1990; 1992:445; The Latino Encyclopedia, 1996:833. 


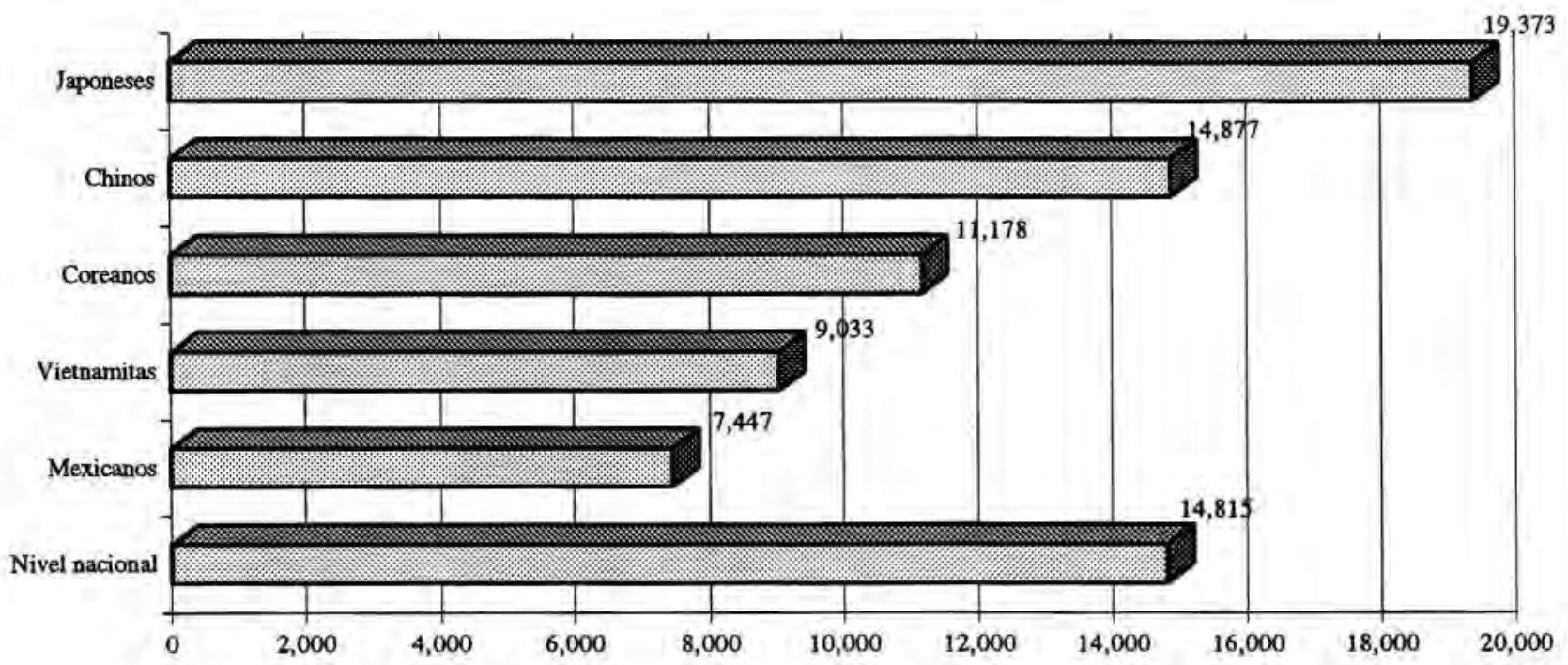

Figura 3. Ingreso percápita, 1989 (en dólares constantes).

Fuente: Bureau of the Census U.S., 1990; The Latino Encyclopedia, 1996:799. 
8.2

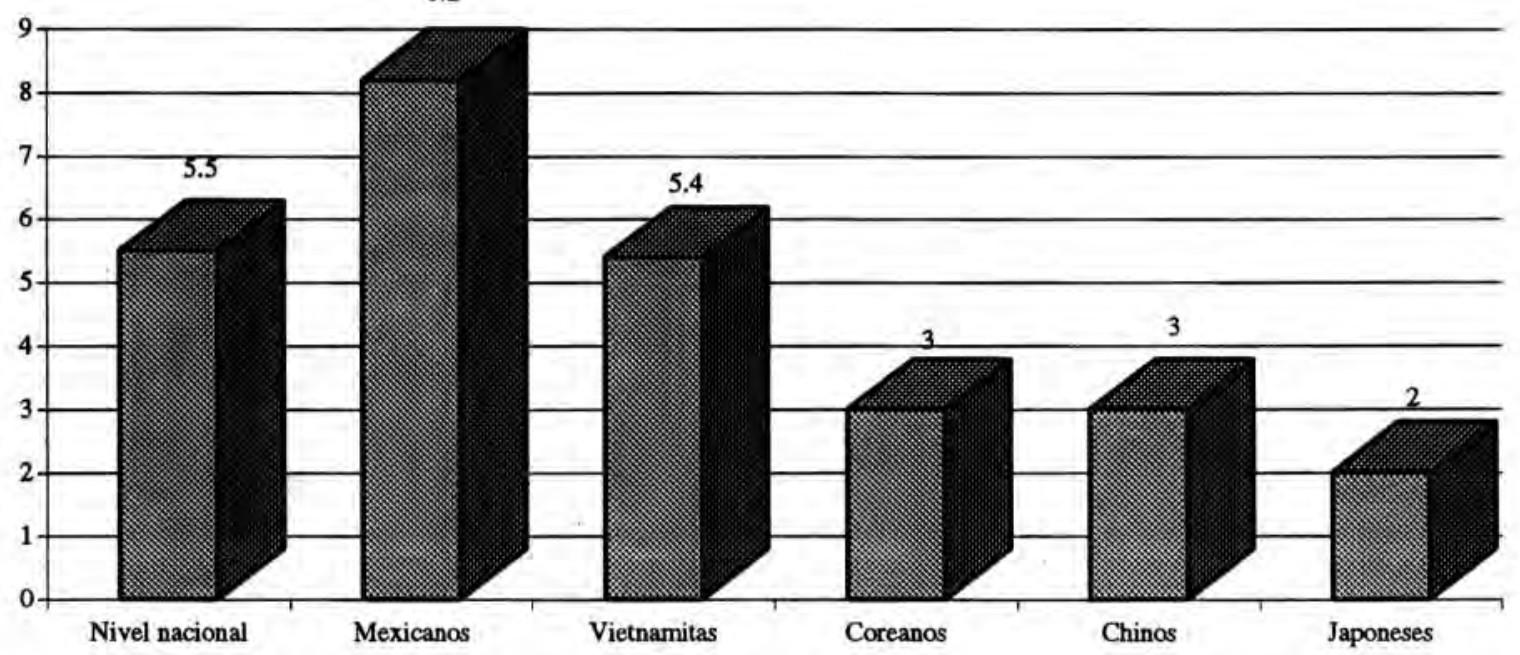

Figura 4. Tasa de desempleo, 1990.

Fuente: Bureau of the Census U.S., 1990; The Asian-American Encyclopedia, 1995:284, 737. 


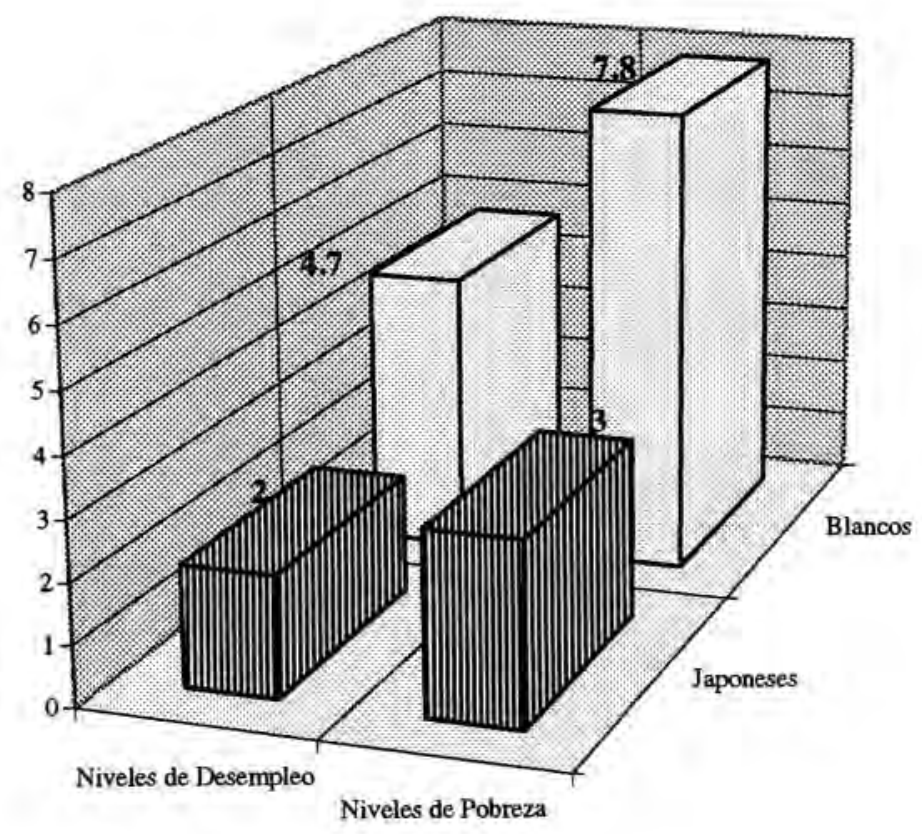

Figura 5. Proporción de personas desempleadas en 1990 y familias bajo el umbral de la pobreza en 1989. Fuente; Bureau of the Census U.S., 1990; 1992: 383,454,459. 
En cuanto a las tendencias exogámicas, y de acuerdo con las observaciones de Sowell en el sentido de que éstas se presentan con más frecuencia entre los estratos más elevados, podríamos anotar que, en el caso de los japoneses, su alto índice de matrimonios contraídos fuera del grupo étnico (50\%) pudiera ser el resultado, por lo menos parcial, de la concentración cada vez más importante de este grupo dentro de los peldaños medios y superiores de la escala social. (The Asian-American Encyclopedia, 1995:684).

En cuanto a la antigüedad de los grupos en los Estados Unidos y los logros obtenidos, las estadísticas nos revelan lo siguiente: los vietnamitas con sólo un $20 \%$ de nativos, es decir, nacidos y, por supuesto, escolarizados en los Estados Unidos, es el grupo, como ya lo hemos podido ver antes, con la más baja posición socioeconómica. Le siguen los coreanos con el $23 \%$, los chinos con el $31 \%$, los filipinos con el $36 \%$ y finalmente, el grupo con mayor concentración de miembros en los estratos medios y superiores de la sociedad, los japoneses con un 67\%. (Bureau of the Census U.S. , 1990, en The Asian-American Encyclopedia, 1995),(Ver figura 6).

En el caso de los mexicanos, la proporción es tan importante como la de los japoneses $(67 \%)$, y sin embargo, su posición socioeconómica, lejos de la de aquellos, es comparable a la de los vietnamitas, a pesar de su poca antigüedad en el país.

La condición social de los mexicanos no sólo mejora menos rápidamente que la de otros grupos étnicos de origen asiático con el paso de las generaciones. Algunos datos nos sugieren que éstos tienden a estancarse socioeconómicamente a partir de la segunda generación. En todo caso esto es lo que nos revela un estudio realizado en el área metropolitana de Los Ángeles-Long Beach en 1970 por el Bureau of the Census U.S. De acuerdo con este estudio la tasa de pobreza entre las familias mexicanas disminuye de la primera generación $(16.0 \%)$ a la segunda $(12.2 \%)$ en la misma proporción que aumenta el ingreso medio familiar por año de una generación $(\$ 7,469)$ a la otra $(\$ 9,530)$. Para la tercera generacion los resultados - por lo menos en lo que respecta a estos dos parámetros-son contrarios a lo que se pudiera esperar. el ingreso medio por familia pierde 231 dolares y la tasa de pobreza se incrementa de una manera poco significativa (12.3\%). En el caso de los chinos y los japoneses, los resultados son más que significativos, espectaculares. De la primera generación a la segunda la proporción de pobres retrocede de un $11.3 \%$ para ambos grupos a un $4.3 \%$ y un 3.0\% en el orden respectivo (Bureau of the Census U.S. 1970:350,352,355).(Ver figura 7).

Así pues, frente a tales contrastes habría que reconocer que no todos los grupos étnicos nacionales con características raciales distintas de las 
que presentaban los grupos de inmigrantes originarios de Europa, llegados a Estados Unidos en el curso del siglo XIX, se esclerosan en los peldaños más bajos de la sociedad. No obstante, y frente a un contraste socioeconómico de esta naturaleza, sería indispensable establecer si estas desigualdades se podrían explicar a partir de un enfoque como el que ofrece el análisis de la estructura de producción y las relaciones sociales de producción que de ésta se desprenden. Si como lo señala Poulantzas, la producción social presupone no sólo la reproducción de los "lugares" dentro de la división social del trabajo sino además la reproducción-distribución de los agentes dentro de esta estructura social (1974:206), habría que ver que a su vez los agentes relegados a la categoría de "ejército industrial de reserva" serían entendidos como una fracción o estrato de la clase obrera, producto de los movimientos alternativos de producción y contracción de la producción y en este sentido, en el sentido estricto de la ley de la variabilidad de la producción capitalista (Cf. Marx, 1985:95108), como un destino inexorable para los agentes menos calificados de la clase obrera y en última instancia como una fatalidad propia a la economía de mercado.

Así pues la posición preponderante de los mexicanos dentro de este espacio social sería considerada desde el punto de vista de la noción marxista de la competencia entre los empleos como el resultado de una contienda económica entre las minorías nacionales. Tenemos pues un resultado, es decir, un "efecto de estructura", como diría Poulantzas, y esto, desde el punto de vista marxista, es lo fundamental. Los análisis de estructura señalan los límites de su perpectiva. ¿En qué sentido? En el sentido que, como lo demuestra Weber y como lo podremos ver más adelante de una manera más detenida, no todas las manifestaciones superestructurales tienen un origen estructural.

No es tanto la teoría de las clases sociales to que pretendemos cuestionar aquí, sin embargo, podríamos decir lo siguiente al respecto: más allá de lo que desde un punto de vista abstracto se pudiera considerar como la subordinación de la reproducción-distribución de los agentes a la reproducción de los lugares o espacios sociales en el campo de las relaciones sociales de producción se encuentran de una manera muy concreta la identidad de los agentes-individuos que se distribuyen a través de estos espacios, la cual nosotros cuestionamos con base en factores subjetivos vinculados con la personalidad cultural de los agentes, factores obviamente superestructurales.

Contrariamente a las sociedades racialmente homogéneas, el carácter multiétnico de la sociedad estadounidense permite observar la distribución de los agentes en la estructura de clase con base en características tan 
visibles como son las raciales. Algo más importante todavía, nos permite seguir mediante análisis retrospectivos la trayectoria de un grupo a través de la misma. En este sentido nos parece más adecuado plantear el problema en términos de distribución de agentes-individuos, pero en un sentido más dinámico que el que ofrece la perspectiva marxista de las clases sociales. En todo caso la realidad empírica en este renglón nos obliga a admitir la teoría de la movilidad social.

Se trata de un punto sobre el que volveremos a su debido tiempo, por el momento nos parece imprescindible reiterar el mismo problema bajo la pregunta siguiente: ¿por qué desde el punto de vista de la distribución de los grupos étnicos-raciales dentro de la estructura del empleo es la serie $\mathrm{X}$ (mexicanos, puertorriqueños, etcétera) y no la serie Y (chinos, japoneses, etcétera) la que ocupa dicho espacio social? siendo que en ambos casos observamos flujos masivos de inmigrantes, ${ }^{11}$ violencia y prácticas discriminatorias y como punto de partida el desempeño de actividades mal remuneradas y de bajo prestigio social.

¿O es que acaso dichas desigualdades sociales podrían estar correlacionadas de una manera directa con una variable como lo es el grado de discriminación racial? Como se podrá ver enseguida, la observación empirica respecto a las prácticas discriminatorias y los procesos de integración socioeconómica relativos a los diferentes grupos átnicos arroja resultados por demás controvertidos.

\section{LA TESIS DE LA DISCRIMINACIÓN RACIAL}

De una manera general podriamos decir que esta tesis se organiza en torno a dos postulados o supuestos fundamentales: 1) los prejuicios raciales y las prácticas discriminatorias constituyen fuerzas que limitan las posibilidades de las minorias no solo de ascenso social sino de verdadera integración económica, política y cultural y, 2) los tratos discriminatorios tienen un impacto relativo en la psicología de los individuos, en la medida que genera procesos de desvalorización e inferioridad y agudizan los conflictos de identidad, lo cual complica aún más los procesos de integracion (Cf. Fredrickson y Knobel, 1980:829-847).

11 De los 15 millones de inmigrantes que ingresan a los Estados Unidos entre 1961 a 1990, la proporción de mexicanos (18\%) fue ligeramente superior a la de los chinos, coreanos y filipinos, la cual suma una proporción de 16.2\%. (Bureau of the Census U.S., 1992:11). 


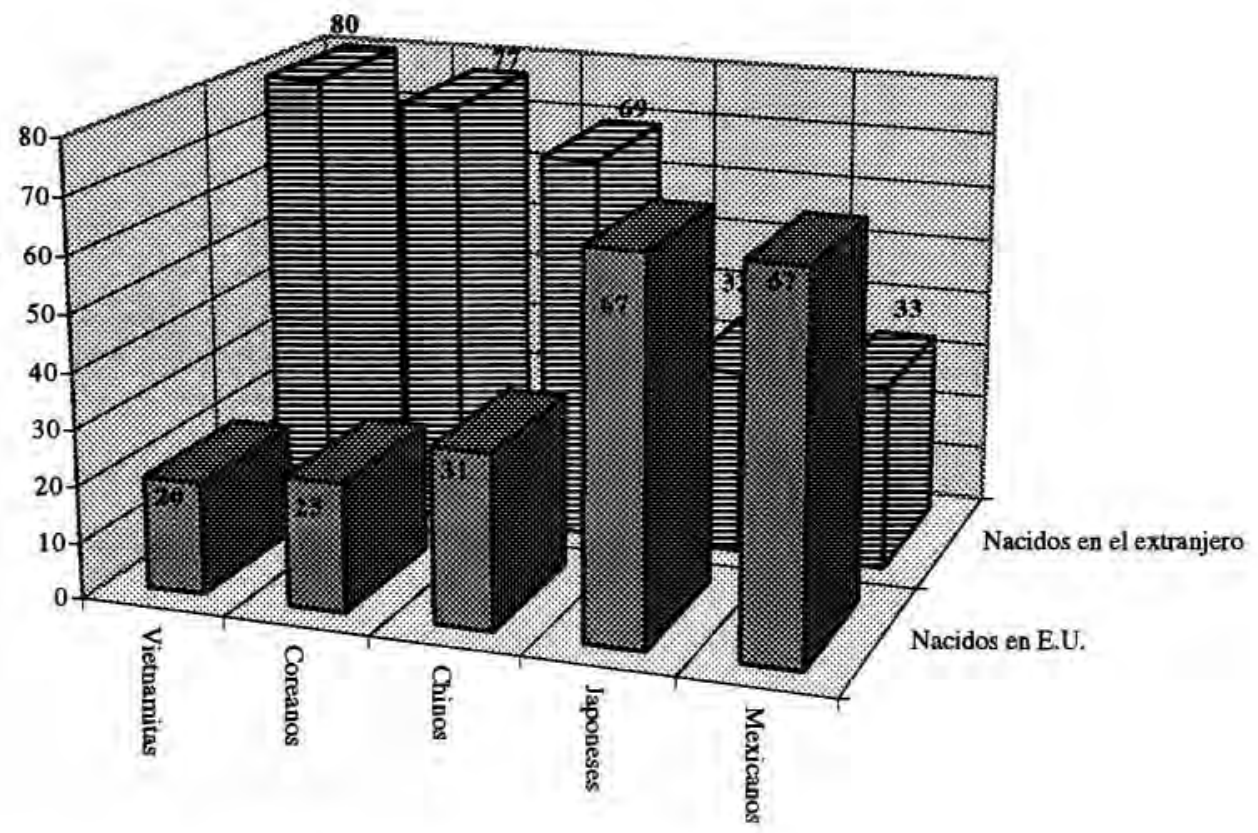

Figura 6. Proporción de personas nacidas dentro y fuera de Estados Unidos, 1990. (Nivel nacional). Fuente: Bureau of the Census U.S., 1990; The Asian-American Encyclopedia, 1995. 


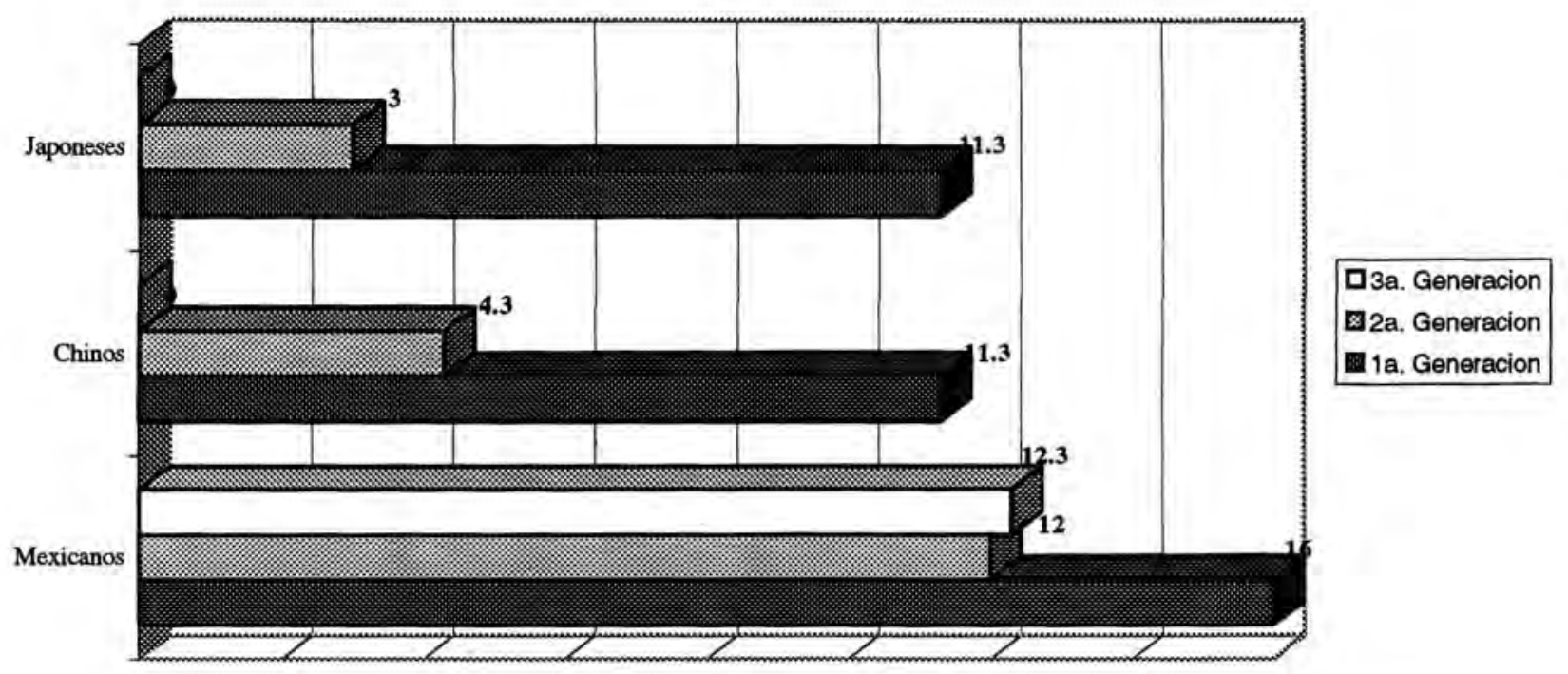

Figura 7. Proporción de familias bajo el umbral de la pobreza por generación, 1970. (Área metropolitana de Los Ángeles-Long Beach).

Fuente: Bureau of the Census U.S., 1970:350, 352, 355. 
Como se podrá observar, el primer postulado señala procesos que tienen que ver con insuficiencias morales por parte de los miembros e instituciones de la sociedad dominante. Se trata de un mecanismo social de dominación. El segundo postulado, por el contrario, señala las consecuencias sociales, morales y psicológicas en las minorías. Son procesos que denuncian daño e insuficiencias por parte de los miembros de las minorías. Nos encontramos entonces frente a un proceso que refuerza a los mecanismos sociales de dominación.

De hecho, la demanda misma de programas compensatorios formulada principalmente por los negros (y detrás de ellos los mexicanos y otros grupos étnicos) durante los años sesenta no es nada ajena a los postulados anotados arriba. Se trata pues de un daño sobre el cual la sociedad receptora ha venido gradualmente respondiendo mediante leyes y políticas correctivas de tipo "guerra a la pobreza" o distribución de empleos públicos por medio de cuotas (afirmative action), ${ }^{12}$ Todos estos programas de ayuda se implementan durante los mejores años del Estado providencia, tanto por gobiernos demócratas como republicanos, a lo largo de los años sesenta y setenta. Ahora bien, todo parece indicar que la libertad con que el Estado se entrega a este tipo de políticas voluntaristas se la otorga un amplio consensus que se venía gradualmente generando a lo largo de un periodo de prosperidad general. Es gracias a esta atmósfera económica que la sociedad dominate modifica su actitud con respecto a los grupos minoritarios. Bajo esta atmósfera las condiciones no pudieron ser más propicias para que algunos grupos étnicos, los más pobres, como los mexicanos, afroamericanos, puertorriqueños e indios nativos, mejoraran su situación socioeconómica (Sowell, 1986;214).

En 1959 , por ejemplo, más de la mitad $(55.1 \%)$ de la población afroamericana, mayores de 16 años, se encontraban por debajo de los niveles de la pobreza. Para 1974, este índice alcanza su nivel histórico más bajo con $30.3 \%$. Como en el caso de los negros, el índice de pobreza entre la población de ascendencia mexicana se "corrige" hacia la baja gracias a una larga coyuntura ${ }^{13}$ que arranca con la segunda guerra mundial y

\footnotetext{
12 La legislación social en favor de las minorías alcanza el sistema educativo. Entre otras leyes podemos citar las siguientes: la "Civil Right Act" de 1964 (institucionalización de la desegregación escolar); la "Bilingual Education Act", de 1968 (educación bilingüe); la "American Ethnic Heritage Act" de 1972 (estudios étnicos) y la "Equal Education Opportunities Act", de 1974 (Igualdad de oportunidades educativas ). Con estas leyes se pretendía incrementar la participación de las minorias ea la formación escolar y universitaria, proceso a través del cual se podrían generar las condiciones de una perfecta "igualdad de Oportunidades".

${ }^{13}$ Se trata del periodo más largo de crecimiento económico que haya conocido la economía estadounidense en toda su historia.
} 
culmina precisamente en 1974, con la llamada "crisis del petróleo". Las consecuencias de la crisis son inmediatas en el caso de los mexicanos, de manera que al finalizar el año fiscal 1974 la pobreza entre éstos se incrementa en $1.1 \%$, el cual pasa de $21.9 \%$ a $23.0 \%$. (Bureau of the Census U.S., 1985).

En 1980, con la envestidura presidencial de Ronald Reagan se inicia una nueva era en la historia económica de los Estados Unidos: la neoliberal. Las consecuencias de la recesión aparejada a la "desregularización" de la economía repercutirán de una manera directa sobre el Welfare State, los niveles del desempleo y la pobreza, principalmente entre las minorías nacionales. En el caso de la población de ascendencia mexicana el nivel de la pobreza crece entre 1979 y 1990 en casi siete puntos porcentuales (Bureau of the Census U.S., 1992).

Tenemos entonces que la calidad de la relación entre la sociedad dominante y los grupos minoritarios depende no sólo de políticas voluntaristas orientadas a elevar la condición socioeconómica de éstos. Más allá de los recursos que el Estado pudiera canalizar en favor de las capas marginadas de la sociedad, la tolerancia o la intolerancia racial por parte de la sociedad dominante dependen, en última instancia, de las coyunturas económicas. Se podría decir que aquellas fluctúan de acuerdo con el comportamiento de la economía. Es así que durante los periodos de crecimiento económico los grupos étnicos mejoran sus niveles de vida, pero este progreso no es exclusivo a ellos, sino general a toda la sociedad. Se trata de un aumento substancial en el nivel de vida de la población en general y no debido, precisamente a una cierta modificación en la distribución de los ingresos. Es esta condición general la que explica la presencia del espíritu de tolerancia en el ámbito de las relaciones raciales. Por el contrario, las manifestaciones recurrentes de intolerancia racial, ver discriminación, resurgen con el descontento popular que generan las dificultades económicas. En todo caso ese es el espectáculo que nos ofrece la historia de la inmigración de los Estados Unidos (Cf. Morison y Commager, 1951; Ertel, Fabre y Marienstras, 1979).

Como ya lo hemos anotado antes, por una razon u otra, al ver diferencias de orden cultural, lingüístico, confesional y racial, todos los grupos étnicos tienen o tuvieron que enfrentar en un momento dado la hostilidad de la sociedad receptora. En cuanto a la intensidad de la discriminación, un especialista del tema nos asegura que ésta no podría explicar por sí misma la evolución socioeconómica de las minorías. Y esto aparece de manera más clara desde el momento que se intenta correlacionar el grado histórico de discriminación con los resultados económicos obtenidos por parte de éstas. Lo que sorprende, dice al respecto el mismo autor, es el 
hecho patente de la poca correlación entre estas dos variables. (Sowell, 1986: 200-201).

Así por ejemplo, las leyes segregacionistas y discriminatorias en contra de los afroestadounidenses, (llamadas Jim Crow) que sin duda alguna han pesado en la conciencia de varias generaciones de negros residentes del sur de los Estados Unidos, podrían encontrar su paralelo en los peores años de legislación en contra de los chinos, años marcados por la violencia de milicias privadas, discriminación jurídica y hostilidad de la ciudadanía (Sowell,1986:200). De una cierta manera, dice un autor, los chinos y los japoneses compartieron con los afroestadounidenses algunas incapacidades asociadas con la raza, el color y una cultura substancialmente distinta de los euroestadounidenses (Fredrickson y Knobel, 1980:830). Sin embargo, entre unos y otros las diferencias socioeconómicas jamás podrían pasar desapercibidas, sobre todo allí en donde las dos comunidades coexisten en gran número. ${ }^{14}$ Lo mismo se podría decir de los mexicanos con respecto a los puertorriqueños, ciu-dadanos estadounidenses desde 1921, entre quienes se puede observar un desequilibrio desfavorable ${ }^{15}$ a pesar de las prerrogativas que les otorga la ciudadanía estadounidense. Una reseña histórica de los atropellos colectivos que estos últimos han sufrido en los Estados Unidos, resulta poco comparable al lado de la de mexicanos, varias veces perseguidos, deportados en masa y no pocas veces linchados, como ocurrió en Los Ángeles de los años cuarenta, en el transcurso de un triste incidente llamado "zoot suit riots", o "motín de los pachucos" (Cf. Mc. Williams, 1972).

De la misma manera sería difícil pretender que la discriminación en contra de los puertorriqueños haya sido de la misma intensidad con la que tuvieron que luchar los japoneses, cuyo ingreso familiar o percápita representa el doble y más en relación con los primeros (Cf. Sowell, 1986:201; Bureau of the Census en The Encyclopedia Latino, 1996; The Asian American Encyclopedia, 1995). O que los puertorriqueños hayan históricamente encontrado un nivel de discriminación comparable al de los negros, cuyos ingresos superan en un $20 \%$ al de los primeros (Sowell, 1986:201).

\footnotetext{
${ }^{14}$ Los Chinos superan ampliamente a los afroestadounidenses en prácticamente todos los parámetros: ingreso promedio familiar (36 259 contra 18676 ); ingreso perćpíta (14 877 contra 9017 . En cuanto a los índices de pobreza y desemplo las estadisticas no pueden ser más claras (3\% contra $11.3 \%$ y $11 \%$ contra $29 \%$ en el orden respectivo) (Bureau of the Census U.S., 1990, en The Asian American Encyclopedia, 1995:284; Bureau of The Census U.S., 1992:383, 445, 454, 459).

is Asi lo demuestran algunos parámetros como el desempleo, y la pobreza (Cf. Bureau of the Census U.S., 1992:40,383 en The Encyclopedia Latino, 1996).
} 
No hay duda en cuanto a que los asiáticos hayan encontrado más barreras económicas y sociales que los blancos originarios de Europa del sur y del este, y sin embargo entre los japoneses observamos mayores ingresos percápita y por familia, y menores tasas de desempleo y pobreza que entre los blancos considerados de una manera general (Cf. supra).

Desde el punto de vista de la teoría de la unilateralidad toda relación causal nos ofrece una explicación aproximativa de la verdad y no una descripción integral del curso real de los hechos (Freund, 1966:182), que es muchas veces lo que se pretende al explicar un fenomeno desde una perspectiva causal. En este sentido podríamos decir que una variable como la que nos ofrece la tesis de la discriminación racial, como cualquier otra variable, sin excepción alguna, implica un punto de vista parcial, un fragmento de la realidad, elegido, entre otros puntos de vista, de manera unilateral y planteado sobre la base de una estimación prubabilística. Todo esto entra, naturalmente, dentro de la teoría weberiana de la posibilidad objetiva y de la causalidad adecuada cuya función es, precisamente, la de pesar el significado de una o varias causas en relación con un hecho singular.

Tenemos pues que frente a un hecho singular como es el de la pobreza crónica de una minoría, específicamente los mexicanos en los Estados Unidos, la descriminación racial, como práctica social constituye un "fragmento de la realidad", una causa cuya significación, válida hasta cierto punto, pierde peso desde el momento que se intenta correlacionar el grado de discriminación histórica con los resultados obtenidos por las minorias. Así pues, todas estas consideraciones de carácter empírico-metodológico nos invitan, por vía de consecuencia, a evacuar del análisis el punto de vista que nos ofrece la tesis de la descriminación racial.

Así pues, una vez señalada dicha insuficiencia explicativa, la interrogante mayor de este trabajo volvería de nuevo al primer plano de la discusión.

\section{EL RACIONALISMO EN LA VIDA ECONÓMICA MODERNA}

Se dice que la conducta económica del hombre puede ser considerada racional cuando éste emplea de la mejor manera sus medios - económicos o humanos- para lograr un fin economico (Brochier, 1988:673).

Nos encontramos frente a una definición que si bien nos señala algo que se podría confundir con la noción de eficiencia, también es cierto que ésta nos indica una actitud que le es especifica a la vida económica moderna. Algunos autores señalan que esta actitud debio aparecer con el surgimiento del capitalismo, pues los fines económicos en la economía 
tradicional se encontraban ahogados en una infinidad de fines subordinados, entre otros, a la costumbre, la moral, la religión (Brochier, 1988:673).

Se podría sostener que no todos estos fines, no económicos, han quedado enterrados con la muerte de la economía precapitalista, que de alguna manera siguen interfiriendo en la conducta economica de todos aquellos grupos sociales que, como diría Weber se encuentran "menos directamente bajo la copa del capitalismo moderno o los que menos se le han adaptado" (1967:57).

La relación de interacción entre el hombre y la sociedad es una verdad inegable como para soslayar ese doble proceso a través del cual el hombre se define con respecto a la vida económica: por una parte, como lo señala Weber, el racionalismo económico se impone en la vida como algo determinado por la misma economía pero, por otra parte, su desarrollo depende de la facultad y disposiciones que tienen los hombres para adoptar ciertas conductas prácticas, consideradas racionales (Weber, 1967:20,21). Que el capitalismo haya encontrado en el racionalismo económico su mejor aliado para su desarrollo es un hecho cabalmente admitido. Lo que es menos admitido es que esta disposición mental, palanca del desarrollo capitalista, haya emergido de una filosofía religiosa específica. Esta es, sin duda alguna, la conclusión última a la que haya legado Weber en sus estudios de civilización y la que, por vía de consecuencia nos autoriza a distinguir en el origen religioso de los pueblos algunas particularidades culturales, específicamente aquellas que se muestran conectadas con el comportamiento económico de los hombres. Nuestro planteamiento es tanto más weberiano que en la Ética protestante y espíritu del capitalismo Weber demuestra de manera positiva la influencia de los valores y las creencias religiosas sobre las conductas humanas. Sin duda alguna, el gran mérito del análisis de Weber, como diría Parson en alguna ocasión, es quizás el de mostrarnos "hasta qué punto los fines y los valores socialmente aprobados en la vida profana varían en relación con las de las filosofías religiosas dominantes de las grandes civilizaciones" (Parson en Merton, 1965:94).

De la misma manera, al explorar el rol de la religión en ciertas minorías étnicas y raciales de Estados Unidos, Donald Young señala una correspondencia estrecha entre los fines y los valores socialmente aprobados en la vida secular y su filosofía religiosa predominante (Young, 1937:204). Si es posible, como lo demuestran Weber y Young, explicar el comportamiento económico de un grupo social a partir de su visión del mundo ¿podríamos nosotros a nuestra vez entender la conducta económica de un grupo étnico como los mexicanos a la luz de una fuerza moral religiosa? 
La pregunta resultaría inadecuada si no reconociéramos la importancia de la religión entre los mexicanos de manera general y de los méxicoamericanos de manera particular. Octavio Paz diría en una ocasión que la religión entre los mexicanos era una práctica predominantemente femenina. La religión entendida como práctica, es cierto, pero como conjunto de ideas, de creencias es un hecho que concieme también a los hombres. ¿Acaso no es esa la tarea primordial de las mujeres, la de iniciar a los niños en la religión, inculcándoles ideas, creencias y fe?

Así pues, independientemente de que los creyentes practiquen, se consideren católicos por convicción o por pura afiliación sentimental, lo importante es reconocer que la moral religiosa suda a través de los poros tanto de las culturas de los pueblos como de las herencias culturales de las minorías nacionales. Como dice Weber, "las ideas religiosas son los elementos más profundamente formadores de la mentalidad nacional, ellas llevan en sí mismas la ley de su desarrollo y poseen su propia fuerza sometedora" (1967:211). Aunque tratar de definir la mentalidad de un pueblo como reflejo puro de la cultura, o visceversa, la cultura como evidencia objetiva de la mentalidad equivaldria a plantear de nuevo el viejo enigma del huevo y la gallina. Sin embargo, lo cierto es que una y otra se ven marcados por ese cuerpo de principios que es la religión.

Es con base en esta idea que Peyrefitte intenta demostrar, desde una perspectiva histórica, las divergencias culturales y económicas existentes entre los países de cultura católica y protestante. Sostiene que dichas divergencias no sólo nacen a raíz de la Reforma sino que además se han ido perpetuando hasta llegar a nuestros días. Si no son las diferencias confesionales el factor directo, reproductor de dicho desarrollo económico desigual, por lo menos lo son, de una manera indirecta, la estructura mental de los pueblos que ambas religiones han contribuido a formar. Si el furor de la iglesia católica dice, no se bubiese desencadenado en contra de la "usura devorante", sin duda, en las naciones latinas de Europa occidental, el crecimiento hubiese sido menos tardado, la inversión creadora de riqueza mejor aceptada, el desarrollo menos convulsivo (1995:101).

Todo parece indicar que la religión católica, como vehículo ético social de valores anticapitalistas, ha contribuido históricamente a frenar el desarrollo económico de las naciones con poblaciones predominantemente católicas. Todavía no hace ni mucho - en 1990 - que el papa Juan Paulo II rompe por primera vez de una manera clara y categórica con la tradición del doble rechazo simétrico hacia el socialismo y el capitalismo. El hecho por sí mismo no hubiese merecido que se le mencionara sino se reconociera la enorme influencia que ejerce la directiva pontifical sobre millones de feligreses quienes sobre todo se muestran más atentos en los países en 
donde el catolicismo tiene mayor arraigo, como es el caso de México y muchos de sus ciudadanos radicados en al norte del río Bravo.

Naturalmente que no podríamos ignorar el rápido crecimiento de las sectas protestantes entre los mexicanos del suroeste de los Estados Unidos como lo podrán atestiguar las 1130 congregaciones fundadas sólo en los últimos veinte años (The Encyclopedia Latino, 1996:1370). Con todo y ello las denominaciones protestantes se encuentran lejos de disputarle el monopolio de las preferencias religiosas a la iglesia católica. De acuerdo con un estudio realizado entre 1989-1990, sólo el 8\% de los mexicanoamericanos nacidos en México serían protestantes, mientras que entre los nacidos en Estados Unidos las preferencias se elevarían al 16\% (The Latino Encyclopedia, 1996:1364). Como se podrá observar dicho fenómeno no deja de ser relativamente nuevo y limitado como para incluirlo dentro de una realidad cultural que no podría ser definida de otra manera que como el resultado específico de un largo proceso histórico a lo largo del cual la iglesia católica ha jugado un papel sin duda muy importante. El hecho es que, como dice un autor, en el suroeste "el catolicismo romano forma parte vital de la cultura latina" (The encyclopedia Latino, 1996:1369).

Pero esto no es todo. Además de la cultura y las mentalidades de los pueblos, la sensibilidad es otro de los ámbitos de la existencia humana en la que la religión, como elemento activo, de alguna manera ha participado en su formación. Como dice Freund, la religión no es más que una antena, entre otras, de la sensibilidad humana; ignorar este aspecto de la vida sería pasar por encima del fenómeno de la cultura (1966:35).

Tenemos pues la impresión que es esta antena, la de la religión, que interfiere en la vida económica de los pueblos, la que la estimula cuando premia las motivaciones racionales, la que la frena cuando se opone de una manera conflictiva con la mentalidad del hombre económico moderno, una mentalidad por demás regida por criterios de rentabilidad y productividad.

Bien dice Roger Bastide que "la sociedad contemporánea es una sociedad industrial y nuestra ideología es una idelogía de la produccion" (Cit. en Raphael, 1977:51).

\section{MARX Y WEBER ANTE EL FENÓMENO DE LA RELIGIÓN}

Se sabe que la religión además de ser el refugio del hombre ante las desaventuras de la vida, ${ }^{16}$ un refugio en el que se enclaustran con más

\footnotetext{
${ }^{16}$ Weber señala en su Economía y sociedad que la necesidad de redensión, en el sentido más amplio de la palabra, es algo natural en las capas en situación negativa de privilegio, y lejana en las capas satisfechas positivamente privilegiadas (1974:389-390). Al lado de esta
} 
frecuencia los pobres, ${ }^{17}$ es una forma cultural que, como dice Gramsci, vehícula una cierta concepción del mundo (1977:400), "Es la teoría general de este mundo, su suma enciclopédica, su lógica en forma popular", diría Marx (1972:41).

Aunque totalmente de acuerdo con esta definición, estamos lejos de considerar las ideas y las creencias religiosas desde la perspectiva de la sociología marxista del conocimiento. Desde la perspectiva marxista son las relaciones de producción que condicionan, de una manera general, el conocimiento y las formas de pensamiento. "No es la conciencia que los hombres tienen de sf mismos lo que determina su ser, sino al contrario, es su ser social lo que determina su conciencia" dice Marx en su Introducción general a la crítica de la economía política (1984). Es de esta manera que las ideas y las creencias religiosas serian entendidas como manifestaciones superestructurales, como reflejo ideológico de situaciones sociales específicas, ellas mismas determinadas, esencialmente, por la infraestructura económica. Pero como la misión de las ideologías es la de reproducir a través de la justificación un orden social (en el marco de las sociedades globales) o una condicion social específica (en el marco de los diferentes grupos y clases sociales), el hombre "alienado" de esta manera especifica contribuye a perpetuar no sólo un orden social sino todavía más aún su espacio social dentro de este mismo orden.

Así, los marxistas reconocen la influencia de los sistemas religiosos sobre el comportamiento del hombre, pero este reconocimiento es negativo. Sobre el plano de las consecuencias para las "masas", la aceptación de una religión sería comparable al sopor que le provocaría a un individuo el consumo de opio. Producto de determinadas relaciones sociales, la religión es definida como el "opio del pueblo", la "realización fantástica del ser humano", la "aureola de este valle de lágrimas" (Marx, 1972:42), una especie de "bête da abattre".

En el marco analítico de los marxistas, el valor de todas estas metaforas se reduce a una simple constatación de un hecho social. Es de esta manera que los marxistas excluyen toda posibilidad de análisis que comporte consecuencias diferenciales, que es el supuesto sobre el cual descansa nuestra investigación. Así pues, una cosa es la justificación de la sociedad

\footnotetext{
generalidad se podría sef́alar la extraordinaria fertilidad que constituye para la religiosidad y el sentimiento de redensión, incluso para los estratos más privilegiados, esos periodos de la vida que se consumen bajo el peso de una desgracia o extrema aflicción.

17 Weber afirma que "toda necesidad de salvación, en el sentido religioso del término es expresión de una 'indigencia' y por eso la opresión económica o social es una fuente eficiente de su nacimiento" (1974:393).
} 
industrial a través de conceptos tales como rentabilidad, productividad, eficiencià, competitividad, etcétera, y otra, (más allá de la justificación de la posición social de los hombres que reza el dogmna de la Divina Providencia cuando identifica la obediencia incondidionada a Dios y la sumisión incondicionada ante su situación social) la valoración que le dan las religiones - y por ende los pueblos-a una noción como la del trabajo, la cual engloba todos estos conceptos. Es en este sentido que Weber nos demuestra cómo una ética religiosa del trabajo - la de los calvinistas y otras sectas próximas a ellos- ha podido no sólo trastocar la estructura de clase de viejas sociedades sino además formar, muy a su pesar, una nueva clase de hombres, la nueva clase empresarial que habria de impulsar con su diktat moral de productividad, rigor y razón el nuevo régimen de producción capitalista. Casi un siglo nos separa de los tiempos sobre los que Weber fundamentara su obra y sin embargo, junto con él podríamos repetir que "sin la difusión universal de las cualidades y los principios de conducta metódica observada por estas comunidades, el capitalismo no sería hoy lo que es" (Weber, 1964).

En los mismos Estados Unidos, teatro de una de las más grandes aventuras económicas del puritanismo, la composición étnica de la estructura de clase de este país, se ha visto transformada a lo largo de este siglo. Judíos sefarditas y ashkenazes, ${ }^{18}$ japoneses y coreanos se han incrustrado poco a poco dentro de las principales esferas de la actividad económica -y política, en algunos casos-y compartir espacios con los blancos de una manera general y los blancos-protestantes-anglosajones (WASP) de una manera particular. ${ }^{19} \mathrm{Y}$ los boat peoples, ${ }^{20}$ en menos de 30 años de presencia dentro del paisaje racial de los Estados Unidos han logrado abandonar poco a poco los pantanos de la miseria a pesar de los obstáculos derivados de su propia desgracia. Ahora bien, todos estos grupos se han distinguido por su tenacidad en el trabajo y no pocos son los autores que ven en esta particularidad el factor responsable de su ascenso social. En el caso concreto de los boat peoples algunos autores destacan un sistema de

\footnotetext{
${ }^{18}$ Se dice que el ascenso socioeconómico de los judíos se debe en gran medida al hecho de que sus valores van ligados a la educación formal (Wilson, 1988:23)

19 El despertar de la etnicidad en los años sesenta alcanzó también a los blancos católicos, ortodoxos y judíos ashkenazes originarios del sur y este de Europa. Con ello, los hyphenated american (americanos de guión) cuestionan la vocación hegemónica de los blancos protestantes originarios del norte de Europa. No obstante, como lo señalan Cazemajou y Martin, los judíos, con no menos de 22 representantes en el congreso y numerosas municipalidades en sus manos, han logrado arrebatarle a los WASP una parcela de poder político (1983:70).

${ }^{20}$ Refugiados vietnamitas que huyen del régimen comunista en pequeñas enbarcaciones a través del mar de China.
} 
valores basados en el trabajo duro, la confianza en sí mismo, el budismo, confusionismo y orgullo familiar (Cf. Caplan et al., 1989).

Desde una perspectiva todavía más amplia, hasta los años sesenta se podía constatar que la "libertad de empresa", el más alto de los principios del capitalismo moderno, había logrado desarrollarse sólo ahí en donde los puritanos habían sido históricamente mayoría. Desde entonces España, Italia y la provincia de Quebec, en Canadá, nada más que para referirnos a los países de tradición católica - excluimos a Francia por las mismas razones que Weber había expuesto en su "Ética protestante...", razones que se fundamentan en el dinamismo empresarial de los huguenote y los judíos y que sin duda alguna siguen teniendo vigencia- ${ }^{21}$ han logrado incorporarse al pelotón de los países desarrollados. Pero esto no impide que cuestionemos la dinámica económica bajo la cual estos países se convierten en receptores de enormes volúmenes de capitales extranjeros o que señalemos la erosión de las creencias religiosas como consecuencia de la promoción del dinero como valor supremo y del progreso del hedonismo. Con todo y ello, hoy en día, no es menos posible distinguir en estos países las evidencias de un cierto rezago en materia de desarrollo económico y social. (Véase especialmente el caso de España y Portugal).

En cuanto a las nuevas potencias económicas, como Japón, Corea y los otros cuatro "tigres" del suroeste asiático, no falta quien los califique de países "ethológicamente protestantes" por su disposición mental a la inovación, la comercialización y la iniciativa económica (Peyrefitte, 1995:404). De una manera más particular Berger, Kolm y Vandermeersch pretenden distinguir en la tradición Búdica y Confusiana de estos países el factor substitutivo de lo que fue el calvinismo en occidente (en Sorman, 1994:208-210). Curiosamente, entre estos países se encuentra el origen nacional de más de una de las nuevas élites empresariales de los Estados Unidos. Este es el caso de los japoneses, de los coreanos y de los chinos, estos últimos originarios en su mayoría, desde 1960, de Hong Kong y Taiwan.

Weber distingue el racionalismo de los protestantes del de los confusianos, en el sentido que, mientras el primero exige una adaptación dentro del mundo, el otro permite violentarlo, dominarlo y acomodarlo a sus nececidades. En este sentido nos preguntamos si acaso los asiáticos, particularmente los chinos, no nos están dando una gran muestra de esa capacidad de adaptación a las nuevas condiciones de vida que les ofrece la sociedad estadounidense.

${ }^{21}$ Se dice que la revolución industrial en Francia fue en gran medida obra de los manufactureros protestantes de Alsacia y los valles Vosguiennes (Cf. Rioux, 1971:51). 
En el marco de algunas naciones del tercer mundo, si nos atenemos a la observación que hace Guy Sorman, la promoción del capitalismo la han tomado a su cargo ciertas minorías religiosas como los sikhs en África oriental, los parsis de Bombay, en la India, los lutheranos en Brasil, los maronitas en África occidental (1994:158).

Hoy, como en los tiempos de Weber, sigue siendo sorprendente constatar el atraso económico relativo de los católicos en el mundo en que estos vivan, ya sea en mayoría o minoría dentro de un país, como es el caso, en primera instancia, de los mexicanos radicados en los Estados Unidos y, en última instancia, de los estadounidenses de ascendencia europea, casi todos ellos originarios de Irlanda, Italia y Polonia, países inminentemente católicos.

En el caso de los primeros, se empieza a observar una ligera ventaja socioeconómica de los protestantes en relación con los católicos del mismo origen nacional. En términos de ingresos y años de escolaridad media, el promedio anual es de $\$ 25000$ dólares y un promedio de educación de 10.8 años para los protestantes contra $\$ 19000$ y 10.4 años para los católicos. Los resultados para la segunda generación de protestantes son todavía más significativos: 27000 dolares anuales de ingreso medio y un promedio de escolaridad de 11.3 años (Greeley en Wilson, 1988:61-62).

En relación con los segundos, John Wilson nos reporta algunos datos que no son tan detallados como sería de esperarse pero que no dejan de ser significativos. Se trata de datos obtenidos a través de varias encuestas realizadas en los años sesenta y setenta en la ciudad de Detroit. En estos estudios no sólo se han encontrado menores proporciones de católicos blancos en los peldaños altos de las clases medias - clase media alta-en comparación con los protestantes blancos, (recuérdese que los censos no incluyen datos que revelen la afiliación religiosa de los encuestados) sino que además estos últimos han reportado mayores actitudes positivas con respecto al trabajo (Lenski en Wilson, 1988:22).

En las investigaciones subsecuentes los resultados fueron todavía más contundentes: 1) aquí, las diferencias encontradas en la primera investigación se amplifican desde que se analiza comparativamente la situacion de los protestantes, tomados en bloque, a la de los católicos, considerados desde el punto de vista de su posición generacional; 2) un resultado análogo se obtiene al comparar aisladamente cada una de las denominaciones más importantes del protestantismo (Convensión de los Baptistas del sur, Iglesia Metodista Unida, sólo para citar las dos más importantes) con los católicos considerados en bloque. Los resultados coinciden con la premisa inicial de la tesis de Weber, según la cual no todos los protestantes comparten la misma ética (Greeley en Wilson, 1988:23). 
Otros datos aseveran que los católicos blancos han venido experimentando una cierta dificultad para asegurar una adecuada representación en los altos niveles de la estructura ocupacional. Para lograr tales niveles, nos reporta el autor, los católicos blancos han tenido que luchar con las barreras discriminatorias de carácter confesional que los separan de las más altas esferas de la actividad política y económica (Herberg in Wilson, 1988:23).

En este sentido, nos parece altamente significativo que en toda la historia de los Estados Unidos, un sólo católico - John F. Kennedy - haya alcanzado la presidencia, la más alta función política del país.

Lo anterior presupone dos cosas: 1) que los católicos blancos -alrededor del $17 \%$ - por una o varias razones están subrepresentados en las altas esferas de la actividad económica y política del país; 2) que por una o varias razones la fracción WASP de la clase dominante sigue dominando el panorama económico y político del país.

En los años setenta el despertar de la etnicidad o de la conciencia de la diferencia étnica —como ya lo habiamos señalado antes- alcanza también a los blancos católicos, a tal extremo que un autor ve en tal fenómeno un conflicto entre la "América protestante" y la "América católica", entre una "élite arrogante", "con-descendiente y falsamente liberal", por una parte, y un mosaico de grupos étnicos blancos originarios de europa del sur y del este, por otra parte. Pero las diferencias no solamente son culturales, de otra manera le hubiese sido difícil al autor conceptualizar el conflicto en términos de "lucha de clases" entre un establishment protestante y "grupos sociales predominantemente pobres y católicos". Está claro que si el autor se permite llevar su visión maniqueista hasta el último de los grados del conflicto social es porque las diferencias socioeconómicas entre ambas "Américas" se lo permiten (Michael Novak en Cazemajou y Martin, 1983:29).

En lo que respecta a la posición desventajosa de los afroestadounidenses, Weber nos ofrece una breve explicación sociorreligiosa, la cual la resume al carácter corybántico de las emociones desarrolladas en sus ritos religiosos. Para Weber tales búsquedas sentimentales actúan en contra de la racionalidad comportamental (1964:170).

\section{OBJETIVIDAD EN EL ESTUDIO DE LA SUBJETIVIDAD}

Parsons sostiene - como Weber - que en su acción humana, el hombre persigue fines, expresa voluntades, obedece a motivaciones y que todos estos conceptos - fines, voluntades, motivaciones- son susceptibles de ser analizados científicamente (Rocher, 1972:39). Como se podrá observar, el estudio de la subjetividad en el objeto de ninguna manera compromete 
la noción de objetividad. Cuando hablamos pues de valores y creencias religiosas, o de existencias guiadas por creencias religiosas, estamos hablando de una actividad humana capaz de actuar en un momento dado no sólo sobre el destino social de los grupos sociales sino también sobre la estructura en el sentido de estimular o detener el desarrollo económico de una sociedad. Es sobre todo en relación con este último punto que Weber nos demuestra, de acuerdo con la opinión de Raymon Aron, que "la actitud económica de los hombres puede ser mandada por el sistema de creencias como el sistema de creencias puede ser mandado en un momento dado por el sistema económico" (Aron, 1967:541).

Emst Troelstsch razona de una manera parecida. Dice que de la misma manera que es importante destacar la influencia que ejerce la vida económica y la formación de las clases y los estratos sociales sobre la vida real de las religiones, así, de la misma manera se debería distinguir dentro de la vida economica las influencias internas y esenciales que la religion ejerce sobre el mundo del trabajo (1991:137).

Nuestra distancia con respecto al determinismo reductor del materialismo histórico no puede ser más clara. Sin duda alguna deben ser numerosos y no menos inextricables los factores que pudieran explicarnos la condición social de un grupo o una minoría nacional como es el caso de los mexicanos de los Estados Unidos. Pero no todos estos factores son, digámoslo de una manera todavía más clara, de carácter económico o estructural, ni mucho menos determinantes como para excluir cualquier otra interpretación causal que no fuese exclusivamente materialista. ${ }^{22}$

Naturalmente que esta última valoración se desprende de una concepción particular de la realidad. De acuerdo con la teoría del conocimiento de Weber, la diversidad de la realidad es infinita, pero no sólo desde un punto de vista intensivo, - lo cual exigiría una regresión causal también indefinida, ya que es todo el devenir que ha finalmente contribuido a la producción del efecto singular-objeto de análisis- sino también extensivo (Freund, 1966:43).

Un ejemplo del carácter extensivo de la realidad podría quedar ilustrado al estudiar las causas de una guerra. Pues bien, de la misma manera que sería imposible excluir del análisis la decisión singular de los hombres de Estado que la deciden, así mismo sería imposible excluir del análisis de las causas de la marginalidad de una minoría, la visión que éstos tienen del mundo. Naturalmente que en estas condiciones, como dice Julien Freund:

\footnotetext{
22 Sin duda alguna la cuestión religiosa es una de las materias sociológicas menos convincentes de Marx. Para Bourdieu las cosas no pueden ser más claras cuando dice: "Weber vio lo que Marx no vio (...), lo que no pudo ver" (Bourdieu, 1987:49).
} 
ningún sabio sabría agotar en su integridad el conocimiento que tenemos de la realidad ni ninguna ciencia estaría en posibilidad de alcanzar la escencia de los fenómenos para juntarlos en un sistema completo que sería el pensamiento fiel de toda la realidad (1966:47.53).

Y si bien es cierto que en principio todos los aspectos y elementos son importantes, ${ }^{23}$ la complejidad misma de la realidad nos obliga en los hechos.. y en virtud de lo que Weber califica de "relacion a los valores", a seleccionar sólo ciertos aspectos, mecanismo a través del cual, al estudiar un fenomeno, determinamos la importancia de $\mathrm{x}$ punto de vista entre $\mathrm{n}$ puntos de vista. En estas condiciones, los resultados de nuestra investigación lejos de aportar un conocimiento completo que abarque el fenómeno de la pobreza entre los mexicanos de los Estados Unidos en su integridad, pretenden lograr un conocimiento, aunque modesto y parcial, no menos interesante y posiblemente novedoso (por lo menos esa es nuestra ambición), y esto en virtud de la poca importancia que otros investigadores hasta hoy le han prestado a ese aspecto de la vida, muy interior, que es precisamente el de la religion y de la ética que ésta segrega, o para decirlo de acuerdo con la vieja formula de Kant, la ética como prolongación ontológica de la religión.

Así pues nuestro planteamiento no tiene otro objetivo que el de determinar, entre otros contenidos característicos de la conducta económica de una minoría nacional, culturalmente católica, que aquellos que pudieran ser imputables a la influencia de los ideales religiosos.

Aunque habría que precisar que el determinante religioso no es más que uno -notese uno - de los determinantes de la vida económica. Weber mismo reconoce que "ninguna ética económica se ha determinado sólo por la religión" (1980:18), que ta "complejidad inumerable de factores", llámense estos geografía, economía, historia, etcétera, están allí para invalidar toda causalidad monolítica, reductora, que se pudiera establecer entre ética religiosa y actitud económica (cf Peyrefitte, 1995:308; Weber, 1980:18; Aron, 1967:541).

El tema de la racionalización, hubiese podido dar pretexto a un sistema o una filosofía de la historia si Weber lo hubiese querido, ya sea en el sentido de un progreso o en el de un mejoramiento ethológico (Freund, 1966:127).

Sin embargo para evitar tal riezgo, Weber plantea el concepto de causalidad en términos de afinidad electiva.

${ }^{23}$ Por ejemplo, sería difícil negar, como lo señala Merton, la enorme importancia que desempeña la escuela en la formación de la personalidad y los ideales estadounidenses. 
En el marco de nuestra investigación, la aplicación de este concepto a nuestro objeto de estudio consistiria en establecer una cierta afinidad electiva entre ciertas creecias religiosas y ciertas actitudes o formas de comportamiento que, desde nuestro punto de vista, nos explicarían, por lo menos en parte el bajo nivel socioeconómico de los mexicanos de los Estados Unidos.

\section{INSTRUMENTAL METODOLÓGICO}

Si nuestro objetivo, es pues, el de fundamentar una tesis en tomo a la influencia, en términos negativos, de las ideas y creencias religiosas en la conducta económica de una minoría étnica de origen mexicano, quedaría por determinar las premisas que sostendrían dicha proposicion. En ese sentido tendriamos que demostrar: 1) la existencia de un determinado particularismo (valores étnicos) en la conducta económica de estaminoría; 2) que dicho particularismo está condicionado por "motivos"; ${ }^{24}$ 3) y que esos "motivos" son inteligibles a la luz de las ideas y creencias religiosas de la misma población-objeto de estudio.

Para lograr tal demostración es preciso recurrir a las categorías de la sociología comprensiva, cuya instrumentación nos permitirá precisamente conciliar el sentido subjetivo ("motivo") y la comprensión racional de la actividad humana (conducta económica).

Bien que de alguna manera el método comprensivo se refiere a la subjetividad del individuo, su objeto propio no es de la lectura de los procesos psíquicos sino más bien el de introducir la racionalidad en la realidad para explicarla y entenderla. Ya que toda comprension tiende hacia la evidencia, nuestra tarea primordial será la de hacer inteligible la conducta económica de la población en cuestión. Dicha inteligibilidad podría ser lograda mediante los siguientes pasos:

1. Reunir dentro de un todo conceptual - tipo ideal - las exigencias lógicas morales - de mayor universalidad y significación cultural-que se desprenden de la ética católica en materia de trabajo y eventualmente de dinero (gasto y ahorro).

Algunos de estos elementos se encuentran resumidos en:

a) los ensayos de sociología religiosa comparada que Weber reúne bajo el título de La morale economique des grandes religions;

b) la "sociología de las comunidades religiosas" que Weber desarrolla en su obra magna titulada Economía y sociedad (1974);

${ }^{24} \mathrm{El}$ concepto mismo de "motivo" se verá definido más adelante. 
c) las referencias a la moral católica que Weber hace en su análisis comparativo de la ética calvinista.

De una manera general revisaremos toda la literatura sociologica que responda a este objetivo. De lo contrario, correríamos el riesgo de colocarnos en la mira de aquella cita celebre de Weber en la que condena a los hombres de ciencia que, por entusiasmo o por moda, "creen precindir de los especialistas" (1967:23). Para ver claro, que mejor que apoyarnos sobre los hombros de los estudiosos del tema. Se trata de una prioridad que de ninguna manera excluye los documentos referenciales que han dado origen a toda esta literatura como es el nuevo testamento, catequismos, encíclicas, misales, manuales casuísticos, etcétera.

2. Como segundo paso buscaremos establecer una relación de verosimilitud entre el tipo ideal antes mencionado con la realidad empírica, a saber, el comportamiento económico de los elementos de nuestro objeto de estudio.

3. En un tercer paso se elaborará un tipo ideal en tomo a un comportamiento económico conforme a la vida económica moderna.

Este nuevo tipo ideal le tomaría algunos de sus rasgos a ese individuo histórico que Weber ha dado a conocer bajo la expresión de "ética capitalista" o "espiritu del capitalismo", definida ésta como una conducta de vida que concieme no solamente a la clase empresarial sino a todos aquellos que intervienen de una manera u otra en el proceso de producción (Cf. Disselkamp, 1994).

4. Relacionar de manera comprensiva el tipo ideal anterior con la realidad empírica, a saber el comportamiento económico de la poblaciónobjeto de estudio, para determinar grados de conformidad o inconformidad con la mentalidad de la vida económica modema.

De hecho la funcion metodologica de un tipo ideal es precisamente la de indicar, en cada caso particular, en qué grado la realidad se aparta de ese cuadro de pensamiento homogéneo e irreal (Weber, 1967:72), de ese todo conceptual, de esa utopía racional que se encierra dentro de un cuadro ideal típico.

Se obtiene un tipo ideal, [dice Weber], acentuando unilateralmente uno o varios puntos de vista y encadenando una multitud de fenómenos aislados, difusos y discretos, que se encuentran ya sea en un gran número, ya sea en menor número, a veces nada, que se ordenan los precedentes puntos de vista escogidos unilateralmente para formar un cuadro de pensamiento homogéneo (Weber, 1967:81). 


\section{CAMPOS DE OBSERVACIÓN}

Por realidad empírica hemos de entender en este estudio la conducta económica de la población de ascendencia mexicana de los Estados Unidos, la cual habremos de observar dentro de dos marcos sociológicos referenciales, dimencionalmente distintos pero complementarios.

La dimensión del primer marco será de carácter macrosociológico, esto es, tomará como objeto de análisis a la población mexicana del sudoeste de los Estados Unidos. La dimensión del segundo marco referencial se limitará a un contexto microsociológico en el cual se tomará como objeto de análisis a la población mexicana de una localidad fronteriza: Caléxico, Califomia, la ciudad gemela de Mexicali.

Se trata de relacionar el contenido de los dos marcos referenciales con el modesto propósito de indicar los puntos de mayor convergencia y significación sociológica. Nos encontramos frente a una situación en la que cada marco o instancia, si se le quiere llamar así, exige su propia técnica de observación.

Para mayor claridad de la exposición cabe recordar que en ambas instancias se persigue el mismo objetivo, el de observar una misma realidad empírica, a saber la conducta económica de los mexicanos y esto a partir de dos indicadores, los cuales plantearemos en términos de actitud o comportamiento con respecto a dos ámbitos de la actividad humana: el del trabajo y el del dinero (gasto y ahorro).

\section{Marco de referencia macrosociológico}

Habíamos dicho anteriormente que este primer marco referencial tomará como base un contexto macrosociológico en el cual se considerará como objeto de análisis a la población mexicana del sudoeste de los Estados Unidos. Dicho análisis involucrará material bibliográfico de carácter histórico, etnográfico, literario, así como datos empíricos logrados a través de encuestas.

Por poblacion-objeto de estudio hemos de referirnos en este apartado a la población de ascendencia mexicana que viva en el sudoeste de los Estados Unidos. Dicha definicion nos la impone el hecho mismo que sea aquí, dentro de esta área geográfica en que reside más de las tres cuartas partes de la población mexicana de los Estados Unidos. La relevancia de este hecho demográfico ha sido obviamente determinante como para que casi toda la literatura sociológica especializada en el tema se refiera a esta parte de la población mexicana radicada en los Estados Unidos. 


\section{Marco de referencia microsociológico}

Como ya to habíamos mencionado, este segundo marco referencial se referirá a un contexto microsociológico fundamentado en una encuesta que tome como objeto a la población mexicana de la vecina ciudad de Caléxico, California.

\section{a) Población objeto de estudio}

De acuerdo con los censos de población de los Estados Unidos en 1990, la ciudad de Caléxico contaba con una población total de 18633 habitantes, de los cuales el $92.9 \%$ fueron censados como personas de ascendencia mexicana, el $2.2 \%$ como anglos, el $2.5 \%$ como asiáticos y sólo $0.2 \%$ como afroestadounidenses (Bureau of the Census U.S., 1990:691,828,926). Aquí la referencia censal a la comunidad hispana carece de importancia significativa pues del $95.2 \%$ que los censos reportan sólo el $2.5 \%$ tiene unorigen hispano distinto al de los mexicanos (Bureau of the Census U.S., 1990:1514). Según la misma fuente, un poco menos de la mitad (47.9\%) de la población de ascendencia mexicana había nacido en México.

En lo que respecta al espectro de la pobreza, una fuerte proporción de sus habitantes perciben ingresos que los coloca estadisticamente por debajo del nivel de la pobreza (32.6\%) (Bureau of the Census U.S., 1990a). Planteado de otra manera, de los 6078 pobres recensados en esta localidad fronteriza, la aplastante mayoría de ellos $(5812)$ son de ascendencia mexicana. (U.S.Bureau of Census U.S., 1990:3217). Aquí, 3 de cada 10 personas de ascendencia mexicana entran dentro de esta categoría social. Si bien es cierto que el fndice local de pobreza entre los mexicanos $(33.5 \%)$ es cinco puntos porcentuales superior al que le corresponde a estos mismos pero a nivel nacional ( $28.1 \%$ ), aquélla es dos veces y medio más importante que en relación con la media nacional (13.5\%) (Bureau of the Census U.S., 1992:456).

Cabe destacar que los altos índices de pobreza y concentración de mexicanos que se observa en Caléxico, es una característica que esta localidad comparte, en mayor o menor medida, con casi todas las ciudades fronterizas. En efecto, Caléxico, al igual que otras ciudades fronterizas como Nogales, Laredo, Eagle Pass, Mc Allen, El Paso y Brownsvilles, figura entre las 22 localidades - de más de 2500 habitantes-más pobres de sus respectivos estados. (Bureau of the Census U.S., 1983:815-822).

Estos datos no sólo ponen en relieve el espectro de la pobreza entre los mexicanos de esta ciudad, también nos ayudan a delimitar la población que deberá conformarse, a nivel microsociológico, en objeto de estudio. 
Otro dato más que sin duda alguna nos hace avanzar en la tarea de delimitación de nuestro universo social es el hecho de que un poco menos de 1259 personas pobres tienen más de 18 años (Bureau of Census U.S., 1990a). ${ }^{25}$ Como podremos ver más adelante, este dato, lejos de ser fortuito indica la edad a partir de la cual aumenta la probabilidad de que una persona se convierta en jefe de familia.

Otro paso interesante en esa dirección podría ser el de cuantificar dentro de este grupo a las personas casadas, su extracción confesional y su posición dentro de la escala generacional. Aquí la pregunta sería cuántos pobres que sean mayores de 18 años y casados se identifican con el dogma de la iglesia católica y entre éstos cuántos han sido escolarizados en México (primera generación) y cuántos en los Estados Unidos (Caléxico), siendo, entre estos últimos, unos hijos de padres mexicanos (segunda generación) y otros de padres méxicoestadounidenses (tercera generación). Desafortunadamente, entre la información colectada hasta hoy, no hay ningún dato que pudiera satisfacer por lo menos a una de nuestras preguntas. Aun así, consideramos que lo más importante por el momento es destacar las características socioculturales de la población-objeto de estudio de donde habremos de extraer los sujetos susceptibles de suministramos el material empírico necesario para realizar esta prueba en los términos señalados en los objetivos.

En este sentido, la población-objeto de estudio deberá comprender a todas las personas de ascendencia mexicana que: 1 ) se identifiquen con el dogma de la iglesia católica; 2) perciban ingresos considerados estadísticamente por debajo del nivel de la pobreza; 3 ) sean mayores de 18 años y jefes de familia.

\section{b) Elección de los informantes}

Hecha esta operación, el siguiente paso, lógico, será el de determinar el número de personas a las que habrá de aplicarse el instrumento de recolección de datos. Aunque, hay que precisarlo desde ahora, aquí, el mayor número de personas encuestadas de ninguna manera podría intervenir como criterio para determinar la calidad de la encuesta. La naturaleza misma no sólo de los datos solícitados - cualitativos - sino además y sobre todo de las técnicas de colecta, procesamiento y presentación de los datos que hemos diseñado para este estudio excluyen la posibilidad de llegar a la generalización a través de la cuantificación y la aplicación de

25 Se trata de un cálculo impreciso. 
una muestra de tipo aleatorio. ${ }^{26}$ Abstracción hecha de la investigación de tipo documental y la operación relacional -nos referimos a los dos marcos sociológicos referenciales-que nos permitirá otorgarle una cierta significación sociológica a los puntos de mayor convergencia, la selección de los informantes se habrá de hacer con base en criterios "razonados" e "intencionados", como dice un autor, y con el cuidado de que la operación no comprometa la noción de representatividad. Finalmente, aquí, lo importante es que de alguna manera los informantes seleccionados así, constituyan en sf una muestra o prototipo de su medio social (Magrassi y Roca, et al. 1980;14-15). Bien dicen Magrassi y Roca que:

dentro de las metodologias cualitativas [...] se hace hincapié, más que en las técnicas de muestreo, en los criterios para la selección de un informante y en los sistemas para el control de la información (Poirier, Clapier y Raybaut, 1983).

Una vez definidas las características de la población-objeto de estudio, tal como lo hemos hecho en el apartado correspondiente, nuestra siguiente tarea es, como es de esperarse, la elección de los informantes. Puesto que nuestra hipótesis de base sustenta la posibilidad de demostrar la influencia de los valores y las creencias religiosas en la conducta económica de los estratos pobres de las comunidades mexicanas - en el sentido preciso de inhibir las estrategias económicas más racionales-, una manera de someter a prueba esta idea podría ser la de observar la conducta económica de nueve jefes de familia sobre la base de la escala generacional, con el objeto de ver en qué medida se pudiera correlacionar el cambio socioeconómíco con el cambio en la actitud comportamental (en términos de distancia con respecto a los dos tipos ideales anteriormente mencionados). Estos nueve jefes de familia, además de contar con las características ya señaladas, estarán conformados por tres series genealógicas de tres cada una (padre o madre, hijo(a) y nieto(a). De esta manera cada jefe de familia de cada serie genealógica deberá pertenecer a una de las tres primeras generaciones. El padre a la primera (escolarizado en México), el hijo a la segunda (escolarizado en Estados Unidos) y el nieto a la tercera. Además, el ritmo de evolución socioeconómica deberá ser distinto para cada una de las series genealogicas. $\mathrm{Si}$ bien es cierto que, para la primera serie genealógica, la condición de pobre deberá ser la variable constante a lo largo de las tres generaciones, en el caso de las dos otras series el espectro de la pobreza se deberá observar como un fenomeno regresivo, es decir,

\footnotetext{
${ }^{26}$ Aŭn así, sería difícil pensar, como lo señala Claude Javeau, que las cifras se puedan situar a un nivel epistemológico superior al de las palabras. (Javeau, 1976:372).
} 
ésta perduraría hasta la segunda generación en una de las dos series y sólo hasta la primera en la otra serie.

\section{c) Naturaleza de la información}

$\mathrm{Si}$, por otra parte, reconsideramos las cosas desde la perspectiva del análisis de la información, nuestros datos se remiten a todo aquello que de una u otra manera nos pudieran revelar el comportamiento económico de los interrogados. Más bien buscaríamos determinar la significación de todos aquellos actos que pudieran estar conectados con tal o cual valor religioso. Se trata de un análisis que se propone precisar cuáles son los valores que están en juego o que han dado origen a tal o cual actividad. De hecho, el objeto propio de la comprensión es el de entender el sentido de una actividad o de una relación.

A Weber "le basta constatar que la actividad humana se orienta de acuerdo con un sentido que habría que comprender para hacerla inteligible (Freund, 1966:82)" "Comprender es discemir la evidencia del sentido de una actividad" (Freund, 1966:84), es también discernir el motivo que ha circunstanciado tal o cual comportamiento.

Al estudiar los motivos que ban circunstanciado tal o cual comportamiento, dice Robert K. Merton refiriéndose al método comprensivo, de hecho no hacemos otra cosa que trabajar sobre racionalizaciones, sobre consecuencias más que sobre las descripciones exactas de los motivos verdaderos. También nos dice que los motivos se pueden referir incluso a casos aislados, y que en consecuencia, lejos de corromper el valor de un estudio de esta naturaleza, dichas racionalizaciones aparecen como prueba de un motivo socialmente aceptado. Como lo señala Kenneth Bruke: "una terminología de motivos refleja una actitud general respecto a los fines y medios y una imagen de la vida ideal" (Cit. en Merton, 1965:373).

Ahora bien, en las condiciones en las que hemos decidido emprender este estudio lo más lógico es que nos preguntemos hacía qué imagen de vida ideal nos habrá de llevar el estudio de los motivos, o bien la terminología de motivos para retomar la expresión de Bruke. Esa es precisamente la función de los tipos ideales. Como instrumentos de mesura, son ellos los que nos habrán de indicar a qué imagen de la vida ideal, a qué tipo ideal se aproxima más el comportamiento de nuestros informantes.

\section{d) Técnicas de observación}

Otra de las aclaraciones metodológicas que se tendrían que hacer, aquí, en este plan, se refiere a la técnica de recolección de datos. Es dentro de este 
orden de ideas, pues, que cabría retomar aquella enunciada unas cuantas líneas más arriba, en el sentido de considerar la terminología de motivos como la piedra angular sobre la que tendremos que cimentar todo el trabajo de interpretación. Ahora bien, dada la naturaleza ecléctica de nuestro enfoque metodológico, dicha terminología no podría encontrarse dentro de otra estructura discursiva más que en aquella que los informantes nos pudieran entregar bajo la forma de relato oral.

La encuesta de tipo etnográfico, manipulada de una cierta manera, y su correspondiente técnica de intervención llamada entrevista "centrada" podrían ser la mejor llave de acceso a esta extructura discursiva. Si la encuesta de tipo etnográfico nos ofrece la ventaja de tratar "el documento biográfico no como un producto acabado sino como una materia prima" (Poirier, Clapier y Raybaut, 1983:65), (lo cual nos da margen para analizar el material en función de las categorías de la sociología comprensiva) la entrevista "centrada", nos brinda una libertad que va totalmente de acuerdo con nuestras necesidades metodológicas: la de explorar algunos aspectos de la vida económica de los narradores, la de focalizar la entrevista sobre situaciones vividas o acontecimientos que pudieran poner de manifiesto algo tan dialéctico como es el comportamiento humano en la medida que si bien es cierto este último se consume objetivamente en el acto, al mismo tiempo es el resultado de mecanismos subjetivos.

Finalmente, son estos mecanismos subjetivos, los que, a través de un análisis comprensivo de motivos, esperamos revelar en este estudio. Con esto debe quedar claramente entendido que no sólo se trata de explicar, sino de comprender, es decir, de interpretar el sentido subjetivo de los hechos estudiados (Weber, cit. en Istas, 1986:95). En una palabra, la comprensión de acontecimientos singulares reales no es más que una interpretación (...) (Kaspers, cit. en Istas, 1986:94), es el proceso a través del cual se asocian acontecimientos mentales con valores, es la llamada "síntesis creativa" (Weber, Cit. en Istas, 1986:96).

La libertad que nos ofrece la técnica de entrevista mencionada garantiza orientar y desarrollar el relato en la dirección de los temas de nuestro interés. Tanto el método como la técnica han sido diseñados para abordar incluso materiales de tipo onírico (sueños con un contenido de alta significación) como crítico reflexivos (las reflexiones críticas que el narrador pudiera efectuar en relación con un acto, tambien de alta significación) (Merton, 1965:61). Se trata de un campo de la actividad humana en que nos parece posible encontrar elementos configurativos de una imagen de vida ideal. En este sentido tanto el método comprensivo como la etnografía nos brindan valiosas posibilidades. 


\section{Práctica religiosa e identidad étnica nacional}

Por otra parte tenemos otro tipo de información que no requerirá del mismo tratamiento dado su alto grado de evidencia objetiva. Este tipo de información, igualmente valiosa que nos revela de una manera manifiesta el grado de religiosidad de los entrevistados, concatena la práctica a la creencia religiosa. "La práctica se opone a la creencia como el acto al pensamiento", dice Isambert (1992:24). Hay actos de la vida religiosa que son públicos y por ello perfectamente observables. En los registros parroquiales las colectividades dejan rastros indelebles de algunas prácticas, sobre todo aquellas que están ligadas al ciclo de vida: bautismo, nupcias, quinceañeras, defunciones. También son observables, aunque por otros medios, algunas otras prácticas como la asistencia a la misa dominical, la confesión o la comunión e incluso ejercicios de carácter espiritual, como la oración. El abanico de prácticas religiosas va desde aquéllas que rozan la tradición, pero que sin por ello pierdan su carácter reflexivo vis á vis de las creencias religiosas, hasta las más fieles interrpretes de la fe. Finalmente, es la fe la que anima a la prática, nos dice de nuevo Isambert (1992:26). En el caso contrario, la falta de la práctica nos indicaría o bien ausencia de este pensamiento o bien impotencia de la misma (Isambert, 1992:24). Frente a una disyuntiva como esta, es pertinente explorar de una manera directa el ámbito de las creencias religiosas por medio de una batería de preguntas abiertas y cerradas. De esta manera evitaremos el riesgo de pasar por encima de latencias poco visibles. Esta última recomendación no valdría la pena mencionarla si no reconociéramos el declive general de la práctica religiosa entre los católicos del mundo de una manera general y de los mexicanos de los Estados Unidos de manera particular. De una manera general, se dice que la asistencia a las parroquias católicas de los Estados Unidos bajó en casi un $20 \%$ como reacción a la encíclica Humanae Vitae publicada en 1968, documento en el cual la iglesia condena el control de la natalidad (Wilson, 1988:20). Como quiera que sea, la crisis de la iglesia católica estadounidense ha sido menos brusco que en paises como en Italia o Francia, este último sometido a un proceso de descristianización que persiste desde los tiempos de la revolución Francesa (Cf. Le FigaroSofres, 1994).

En una sociedad multiracial como es la estadounidense, en donde la autopercepción de la diferencia con base al color y la cultura pesa obligatoriamente en la conciencia de los individuos, la adhesión al catolisismo ha sido un factor más de diferencia cultural, diferencias que los mexicanos mismos no dejan de subrayar. El culto público a la virgen de guadalupe, a través de murales y otras manifestaciones -incluso políticas- (el 
movimiento chicano, por ejemplo fue encabezado con el estandarte de la virgen de Guadalupe) es la prueba, quizás la más contundente, de ese deseo, de esa "obstinada y casi fanática voluntad de ser", para emplear una expresión muy conocida de Octavio Paz (1959:13). Que la identidad de los méxico-americanos marche anclada a las naves de la iglesia católica es un hecho histórico que se ha prolongado aun hasta nuestros días ${ }^{27}$ y esto a pesar de la vacuidad relativa que han venido experimentando en las últimas dos décadas. Pero como dice Paul Thibaud, ¿qué significa realmente ese vacío progresivo en el que han caído las iglesias catolicas? ¿Significa indiferencia o cambio en cuanto a la forma de la práctica propiamente? De manera general, el autor responde que no es porque no se practique la religión de una cierta manera que las creencias religiosas hayan desaparecido de la conciencia de los católicos (1988:408). Además, "la audiencia de una iglesia y, de una manera más amplia, el discurso religioso, no se mide por el número de practicantes" (Augé, 1988:50).

Por otra parte, sería justo que nos preguntáramos si acaso no estamos asistiendo al fin de ese vasto proceso de secularización de la vida (o "desencantamiento del mundo" para repetir la famosa expresión de Weber), que ha acarreado consigo el capitalismo con el racionalismo y la intelectualización creciente de todas las actividades humanas. Los signos de un posible retour en force de la espiritualidad se multiplican aqui (Estados Unidos) y allá (Europa occidental), como señales premonitorias de aquella sentencia casi profética que hiciese André Malraux: "el siglo XXI será religioso o no lo será".

Por último cabe anotar que si bien Caléxico comparte algunas características socioeconómicas y demográficas con más de 22 localidades del suroeste, esto no nos autorizaría a adjudicarle a esta ciudad fronteriza un carácter representativo. Por su posición geográfica limítrofe frente a México, por su calidad de ciudad gemela con población predominantemente mexicana y con altas tasas de pobreza, los resultados de nuestra encuesta podrían operar como indicadores en cuanto a la posible validez de estos resultados para otras poblaciones del sudoeste dominadas demograficamente por mexicanos. Para que los resultados de esta encuesta puedan lograr un mayor grado de generalidad, la experiencia se tendría

27 Tómese esto en sentido fugurado ya que gran parte del fervor religioso de los mexicanos
del suroeste, a diferencia de los católicos de origen irlandés, italiano y polaco, se expresa en
el hogar a través de altares, imágenes de vírgenes y santos y sus respectivos accesorios como
velas, etcétera. (The latino encyclopedia, 1996:1367). En relación con la importancia de la
religión como vector de identidad y de los templos como centros comunitarios de solidaridad
étnica véase Laura L. Becker, Ethnicity and religion; en Encyclopedia of American Religion. 
que repetir en otras latitudes, unas en el suroeste profundo y otra por lo menos en una gran urbe, por ejemplo Los Ángeles. Por suroeste profundo habría que entenderlo como el lugar de origen histórico de muchos mexicanos que hoy en día viven en las grandes urbes. Los Ángeles, con la mayor concentración de población de origen mexicano (1 391000$)$ es la principal ciudad-destino de muchos de estos últimos que por falta de oportunidades han tenido que abandonar sus lugares de origen, por lo general pequeñas localidades, muchas de ellas sujetas a una actividad preponderantemente agrícola y por ende generadoras de empleos efímeros, penosos y mal remunerados. Aqui el espectro de la pobreza llega a cubrir, en algunos casos a más del $50 \%$ de la población. (Cf. Bureau of the Census U.S., 1983:813-823, 875, 912-917).

Otra de las características o común denominador de todas estas pequeñas y medianas comunidades, como es el caso de Laredo, Texas con una población de 91449 y con $93 \%$ de población mexicana, es la escasa relación de interacción con la población anglosajona. Aquí, como en Caléxico, Eagle Pass, Nogales, Brownsville, Mc Allen la relación de los mexicanos con la sociedad dominante pasa en gran medida a través de las instituciones.

De una cierta manera, los mexicanos concentrados en las grandes urbes tienden a repetir este mismo patrón demográfico. El este de Los Ángeles, con más de 110000 , casi todos ellos mexicanos (94.1\%) es el gueto mexicano más grande de los Estados Unidos. Tanto aquí, como en cualquier otra ciudad fronteriza o pequeña localidad con menos de 22000 habitantes y con más del $90 \%$ de personas de origen mexicano la proporción de personas pobres va desde un 23.3\% (este de Los Ángeles) hasta un 63.4\% (Alton, Texas), pasando por Laredo (34.5\%) y Eagle Pass $(39.5 \%$ ) en Texas (Cf. Bureau of the Census U.S., 1983:813, 814, 816-823, 875, 912-917).

Así pues desde una perspectiva comparativa más amplia, la validez de las conclusiones iniciales o, dicho de otra forma, la significación sociológica de cada una de las proposiciones generadas a través del primer análisis comparativo (contex to micro y macrosociológico) dependerían a largo plazo de la regularidad con la que éstas se pudieran observar en el marco de las otras encuestas locales. Se trata de un largo itinerario de trabajo que podría recordar grosso modo la serie de estudios sobre la pobreza que llevarían a Oscar Lewis del campo a la gran ciudad. Así pues, fuera de las reservas que nos pudiera inspirar la noción de la cultura de la pobreza, sería difícil negar que parte de este andamiaje metodologico le debe algo a la obra de Lewis 


\section{BIBLIOGRAFIA}

ACUÑA, Rodolfo.1976. Occupied America: The Chicanos Struggle toward Liberation. Harper and Row. Nueva York, N.Y.

ALBA, Richard. 1990. Ethnic Identy: The transformation of White America. Yale University Press. New Haven.

ARON, Raymon, 1967. Les Etapes de la Pensée Sociologique. Editions Gallimard. París.

AUGÉ,Marc. 1988. "Le retour du religieux", en Enciclopedia Universalis. París, Francia.

BOURDIEU, Pierre, 1987. Choses dits, Les editions de minuit. París.

BOUTANG, Garson y Silberman. 1986. Economie Politique des Migrations Clandestines de Main-d' oeubre. Editions Publisud, París.

BROCHIER, Hubert. 1988. "Rationalité économique", en Enciclopedia Universalis, París, Francia.

Bureau of the Census. U.S. Department of Commerce.1970. Census of Population. Social and Economic Characteristics. National Origin and Language, Subject Report. Government Printing Office. Washington, D.C.

Bureau of the Census. U.S. Department of Commerce. 1978. Historical Statistics of the United States. Colonial Times to 1970. V.I.

Bureau of the Census. U.S. Department of Commerce. 1983. Conditions of Hispanic in America Today. Washington, D.C.

Bureau of the Census. U.S. Department of Commerce. 1985. Statistical Abstract of the United States. Governmement Printing Office. Washington, D.C.

Bureau of the Census. U.S. Department of Commerce. 1990a. Census of Population and Housing Summary. Washington, D.C.

Bureau of the Census. U.S. Department of Commerce, 1990b. Census of Population. General Population Characteristics. California.Washington, D.C.

Bureau of the Census. U.S. Department of Commerce.1990c. Census of Population. Social and Economic Characteristics. California.Washington, D.C.

Bureau of the Census, U.S. Department of Commerce, 1991. Statistical Abstract of the United States. Governmement Printing Office. Washington, D.C.

Bureau of the Census. U.S. Department of Commerce. 1992. Statistical Abstract of the United States. Governmement Printing Office. Washington, D.C. 
Bureau of the Census. U.S. Department of Commerce. 1993. County and City Data Book. Washington, D.C.

Bureau of Census. U.S. Department of Commerce. 1994. Statistical Abstract of the United States. Governmement Printing Office. Washington, D.C.

CAPLAN, Nathan, et al. 1989. The Boat People and Achievement in America. The University of Michigan Press. Michigan.

CAZEMAYOU, Jean Pierre y Martin. 1983. La Crise du Melting-pot. Ethnicité etIdentité aux Etats-Unis, de Kennedy à Reagan. Editions Aubier Montaigne. París.

DISSELKAMP, Annette. 1994. L'étique Protestante de Max Weber. Presse Universitaire de France. Paris.

ERTEL, Fabre y Marienstras. 1979. En Marge, Sur les Minorites des Etats-Unis. Editions Maspero, París.

FREDRICKSON M. George y Dale T. Knobel, 1980. "History of Prejudice and Discrimination", en: Harvard Encyclopedia of American Ethnic Groups. The Belknap Press of Harvard University Press, Cambridge, Massachusetts y Londres, Inglaterra.

FREUND, Julien. 1966, Sociologie de Max Weber, Ed. Presse Universitaire de France. París.

GOBINEAU, Joseph Arthur. 1854. Essai Sur L'Inegalite des Races Humaines, Librairie de Paris. París.

GRAMSCI. 1977. Gramsci dans les Textes. Recopilación realizada por Francois Ricci. Editions Sociales. París.

GRIER, W.H., Cobbs, P.M.1968. Black Rage. Basic Books. Nueva York. GREELEY, Andrew. 1988. "Defection Among Hispanics". en : America 159 (julio 30, 1988).

HODGKINSON, L. Harold. 1986. California: The State and its Educational System. The Institute for Education Leadership. Washington, D.C.

ISAMBERT, Francois-André. 1992. De la Religion à l'étique. Les editions du Cerf. París.

ISTAS, Michel. 1986. Les Morales, selon Max Weber. Les editions du Cerf. París.

JAVEAU, Claude. 1976. "Le Terrorisme du Nombre". Revue International de Sociologie. Bruxelles.

Le Figaro-Sofres. 1994. "Les Francais, la foi et l'Eglise"; en: Le Figaro, (diario). 20 de diciembre de 1994, París.

LÓPEZ y Rivas, Gilberto.1973. Los chicanos: una minoría nacional explotada. Ed. Nuestro Tiempo. México, D.F. 
MAGRASSI, Guillermo, Roca, Manuel, et al, 1980. La historia de vida. Centro Editor de América Latina. Buenos Aires.

MALDONADO-Denis. 1976. En las entrañas: un análisis socio-histórico de la emigración puertorriqueña. Ed. Casa de las Américas. La Habana.

MARX, Karl, 1972. "Critique de la Filosophie du Droit de Hegel", En: Sur la Religion. Editions Sociales. París.

- 1984. Introducción general a la crítica de la economía política/1857. Decimoctava edición. Ediciones de Pasado y Presente, México, D.F.

- 1985. Le Capital. Livre I sections V á VIII. Flammarions, París.

Mc WILLIAMS, Carey. 1972. Al norte de México. Ed. Siglo XXI. México, D.F.

MERTON, K. Robert. 1965. Elements de Théorie et de Méthode Sociologique, Ed. Plon, 2a. Edición, París.

MOORE, J. W. 1972. Los mexicanos de los Estados Unidos y el movimiento chicano. Ed. Fondo de Cultura Económica. México, D.F.

MORISON Samuel y Commager Henry. 1951. Historia de los Estados Unidos de Norteamérica, tomo II. Ed. Fondo de Cultura Económica. México, D.F.

MORGANTHAU, Tom. Avril, 1995. Newsweek, Review, Nueva York.

PAZ, Octavio. 1959. "El pachuco y otros extremos", en El laberinto de la soledad. Ed. FCE, Colección Popular. Madrid.

PEYREFITTE, Alain. 1995. La Société de Confiance. Essai sur les Origines et la Nature du Développement Editions odile Jacob. París, Francia.

POIRIER, J. Clapier-Valladon, S. y Raybaut, P. 1983. Les Récits de Vie. Théorie et Pratique. Presse Universitaire de France. París.

POULANTZAS, Nicos. 1974. Les Classes Sociales dans le Capitalisme Aujourd' hui. Editions du Seuil. París.

RAPHAEL, Freddy. 1977. "Les Sciences Humaines ou la Tentation du Rationalism". En Le Modèle de l'occident. Données et débats. Ed. Presse Universitaire de France. París.

RIOUX, Jean Pierre. 1971. La Revolution Industrielle (1780-1880). Editions du Seuil. París.

ROCHER, Guy. 1972. Talcon Parsons et la Sociologie Americaine. Presse Universitaire de France. París.

ROSE Amold. 1951, L'origine des Préjugés. Unesco. París.

SORMAN, Guy, 1994, Le Capital, Suite et Fins. Editions Fayard. París, Francia. 
SOWELL, Thomas. 1986. Race, Politique et Économie, une Approche International, Ed. Presse Universitaire de France. Paris.

The Asian-American Encyclopedia. 1995. Published by Marshall Cavendish Corporation. North Bellmore, Nueva York.

The Latino Encyclopedia. 1996. Published by Marshall Cavendish Corporation. Tarrytown, Nueva York.

THIBAUD, Paul. 1988, "Le Catholicisme Contemporain". En Enciclopedia Universalis, France. París.

TROELTSCH, Emst. 1991. Protestantisme et Modernité. Editions Gallimard, París.

WEBER, Max. 1965. Essais sur la Théorie de la Science, Ed. Plon. París.

- 1967. L'hetique Protestante et l'esprit du Capitalisme, Ed. Plon, 2a. Edición, París.

- 1974. Economía y sociedad. Ed. Fondo de Cultura Económica. 2a. Edición. México, D.F.

- 1980. "Rasgos principales de las religiones mundiales",en: Sociología de la religión. Ed.Fondo de Cultura Económica. México, D.F.

WILSON, John. 1988. "The Sociological Study of American Religion" en: Encyclopedia of the American Religous. Vol I. Ed. Charles Scribner's Sons. Nueva York.

YOUNG, Donald. 1937. American Minority Peoples. Harper, Nueva York. 